\title{
The beetle fauna (Insecta, Coleoptera) of the Rawdhat Khorim National Park, Central Saudi Arabia
}

\author{
Mahmoud S. Abdel-Dayem', Hassan H. Fad², Ashraf M. El-Torkey², \\ Ali A. Elgharbawy ${ }^{1,4}$, Yousif N. Aldryhim', Boris C. Kondratieff', \\ Amin N. Al Ansi', Hathal M. Aldhafer'
}

I King Saud University Museum of Arthropods (KSMA), Plant Protection Department, College of Food and Agriculture Sciences, King Saud University, P.O. Box 2460 Riyadh 11451, Saudi Arabia 2 Entomology Department, Faculty of Science, Ain Shams University, Cairo, Egypt 3 Plant Protection Research Institute, Agriculture Research Center, Giza, Egypt 4 Zoology Department, Faculty of Science, Al Azhar University, Nasr City, Cairo, Egypt 5 Department of Bioagricultural Sciences and Pest Management, Colorado State University, Campus Delivery 1177, Fort Collins, Colorado, U.S.A. 80523

Corresponding author: Mahmoud S. Abdel-Dayem (mseleem@ksu.edu.sa)

Academic editor: C. Majka | Received 22 August 2016 | Accepted 17 January 2017 | Published 7 February 2017

http://zoobank.org/8ECC0674-017A-4858-8BE8-DDD05COD7CF6

Citation: Abdel-Dayem MS, Fad HH, El-Torkey AM, Elgharbawy AA, Aldryhim YN, Kondratieff BC, Al Ansi AN, Aldhafer HM (2017) The beetle fauna (Insecta, Coleoptera) of the Rawdhat Khorim National Park, Central Saudi Arabia. ZooKeys 653: 1-78. https://doi.org/10.3897/zookeys.653.10252

\begin{abstract}
This study was conducted as a part of a comprehensive baseline survey of insect biodiversity of Rawdhat Khorim National Park (RKNP), Central Kingdom of Saudi Arabia (KSA). During this study a total of 262 Coleoptera species belong to 182 genera in 35 families were identified, of which 247 are named at a species level. Fifteen species (6.0\%) are apparently endemic to KSA. Thirty-eight species are new to the known beetle fauna of KSA, including 25 species reported from the Arabian Peninsula for the first time. The families Tenebrionidae ( 45 species), Scarabaeidae ( 34 species), and Carabidae (27 species) were the most species rich families. About $37 \%$ of the beetle abundance was represented by species of Scarabaeidae, especially Aphodius ictericus ghardimaouensis Balthasar. Karumia inaequalis Pic (Dascillidae) was also an abundant species. Approximately $43.5 \%$ of beetle species collected during this study are considered very rare taxa in RKNP. The RKNP beetle fauna shows more affinity to Sahro-Arabian (36.4\%), Afrotropical-
\end{abstract}

Copyright Mahmoud S.Abdel-Dayem et al. This is an open access article distributed under the terms of the Creative Commons Attribution License (CC BY 4.0), which permits unrestricted use, distribution, and reproduction in any medium, provided the original author and source are credited. 
Sahro-Arabian (17.4\%) and Palaearctic-Sahro-Arabian (10.5\%). Twenty-three species (9.3\%) are considered cosmopolitan or subcosmopolitan. The data on month of collection, method of collection, and abundance status within RKNP, together with the distribution within KSA and the general distribution (zoogeography) of each species are presented.

\section{Keywords}

Arabian fauna, distribution, endemic species, new records, zoogeography

\section{Introduction}

Beetles (Coleoptera) are considered the most taxonomically diverse insect group that comprises major components of ecosystems in terms of biomass, species richness and ecological roles (Stack 2015). About 400,000 species have been described (Hammond 1992), comprising about 25\% of the Earth's total animal diversity (Rosenzweig 1995; Hunt et al. 2007). Beetles play important roles in pollination, herbivory, granivory, predator-prey interactions, decomposition and nutrient cycling, and soil disturbances (Huffaker and Gutierrez 1999).

The foundation of our knowledge of the beetles of the Kingdom of Saudi Arabia (KSA) was presented by various authors in the series "Fauna of Saudi Arabia," currently published as part of the "Fauna of Arabia" (Wittmer and Buttiker 1979- to date). Additionally, sixteen years ago, Al-Ahmadi and Salem (1999) listed 1,343 beetle species from KSA. Additional data on the beetles in KSA are available in the Catalogue of Palaearctic Coleoptera (Löbl and Smetana 2003-2007).

Rawdhats, naturally occurring moist basins, are one of the major components that considered as biological cores in the hyper-arid ecosystems of Central KSA (Tag ElDin et al. 1994; Al-Farraj et al. 1997; Alfarhan 2001; Al-Qarawi 2011). The flora and fauna of these unique habitats are under constant threat due to increased anthropogenic activities (Al-Nafie 2007; Al-Qarawi 2011). However, relatively little is known about their insect fauna (e.g., Al Dhafer and Platia 2013, Al Dhafer et al. 2016; Sharaf et al. 2013; Alqarni et al. 2015; Abdel-Dayem et al. 2015, 2016) that contribute to the faunal biodiversity of KSA.

Rawdhat Khorim National Park (RKNP) in Riyadh Province is important element in the conservation network of KSA and its landscape is characterized by relative diverse pristine native plant communities. (Tag El-Din et al. 1994; Al-Farraj et al. 1997; Alfarhan 2001; Al-Qarawi 2011). Recent studies of the insects occurring in RKNP have revealed several new taxa, Coleoptera: Dicronychus latifahae (Elateridae) (Al Dhafer and Platia 2013); Reichardtiolus aldhaferi (Histeridae) (Lackner 2014); Boromorphus saudicus (Tenebrionidae) (Schawaller et al. 2013); and Hymenoptera: Tetramorium saudicum (Formicidae) (Sharaf et al. 2013).

The objective of the current study was to provide a comprehensive list of the beetles from one of the more unique habitats in the world, specifically RKNP contributing to the knowledge of the beetle fauna of KSA and the Arabian Peninsula in general. 


\section{Materials and methods}

\section{Study area}

The Rawdhat Khorim National Park is situated in the northeastern Riyadh Province of Central KSA (Fig. 1a). This is part of the Najd Plateau, a sedimentary rectangular plateau of Saudi Arabia. It covers an area of $24 \mathrm{~km}^{2}$ and located about $95 \mathrm{~km}$ northeast of the capital of Riyadh $\left(25^{\circ} 23^{\prime} \mathrm{N}, 47^{\circ} 17^{\prime} \mathrm{E}, 560\right.$ m.a.s.l.). It is a densely vegetated alluvial basin (Vesey-Fizberald 1957) (Figure 1b) supporting a characteristic floral community in the hyper-arid desert of central Saudi Arabia (Al- Farraj et al. 1997; Alfarhan 2001). This area has low rainfall, but drainage from surrounding foothills of the adjacent highlands provides additional moisture forming temporary water pools and high plant diversity occurs during spring (Al- Farraj et al. 1997).

\section{Climate}

The climate of RKNP is characterized by a hot summer and a mild winter with an average relative humidity of $33 \%$. The average annual temperature is $26^{\circ} \mathrm{C}$, June to August is the hottest period of the year $\left(35-37.4^{\circ} \mathrm{C}\right)$ and December to February is the coldest $\left(14.6-15.7^{\circ} \mathrm{C}\right)$. The average annual precipitation is $122 \mathrm{~mm}$, the highest amount of precipitation occurs during March and April (30 and $27 \mathrm{~mm}$, respectively), while no rainfall occurs during June to September (Sharaf et al. 2013).

\section{Flora}

The flora of RKNP includes a total of 153 plant species belonging to 32 families (Alfarhan 2001). The vegetation is complex consisting of perennial and annual herbs, shrubs and trees (Al-Farraj et al. 1997). Matricaria aurea (Loefl.) Sch.-Bip. (Compositae)), Plantago boissieri Hausskn. \& Bornm., P. ciliata Desf. (Plantaginaceae), and Phalaris minor Retz. (Poaceae) are the dominant annual herbs (Al-Farraj et al. 1997; Alfarhan 2001). Acacia ehrenbergiana Heyne, A. gerrardii Benth. (Fabaceae), Calotropis procera (Aiton) W.T. Aiton (Apocynaceae), Lycium shawii Roem. \& Schult. (Solanaceae), Rhazya stricta Decne. (Apocynaceae) and Ziziphus nummularia (Burm. f) Wight \& Arn. (Rhamnaceae) are the dominated shrub and trees (Al-Farraj et al. 1997). Plant growth is higher during spring than in other seasons (Al- Farraj et al. 1997).

\section{Beetle collection}

The species listed here are based on the survey that was conducted biweekly from October, 2011 to September, 2013 in the RKNP. The material was collected using a variety 

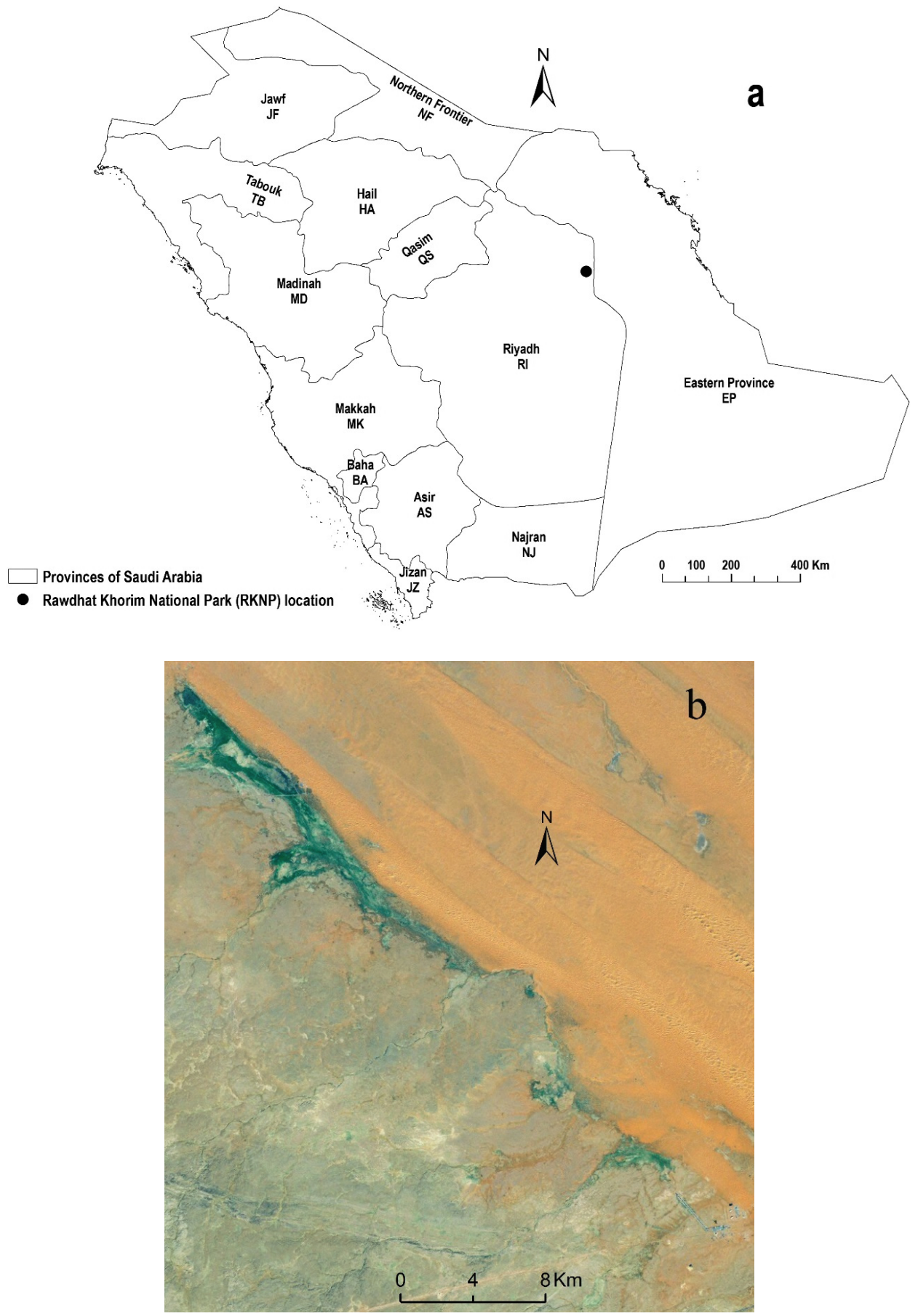

Figure I. a Map showing the provinces and geographic location of Rawdhat Khorim National Park within the Central Region of Kingdom of Saudi Arabia b Photo of Rawdhat Khorim National Park (Produced by ArcMap 10.4). 
of collecting methods including pitfall trapping (PT), UV-light trapping (LT), Malaise trapping (MT), net sweeping (SW), beating vegetation (BV), vacuuming (VC), and hand-picking (HP). All collected beetles were sorted, identified and deposited in the King Saud University Museum of Arthropods (KSMA), College of Food and Agricultural Sciences, King Saud University, KSA.

\section{Species format and arrangement}

Species identification is based on specialists "see Acknowledgments" and numerous publications not included here. Beetles were not being identified to the species level were included in the study if specimens were morphologically different from other (congeneric) species. The identified species are arranged systematically to subfamily level and alphabetically thereafter. The classification and nomenclature of subfamilies and higher levels follows Bouchard et al. (2011). The valid name followed by the author and date of publication for species were given and these were not cited in the reference section and they can be found in the Catalogue of Palaearctic Coleoptera (Löbl and Smetana 2003-2007). The world distribution for each species is indicated as two capital letters for each country (according ISO 3166: http://www.iso.org/iso/ country_codes). The world distribution is based mainly on Catalogue of Palaearctic Coleoptera (Löbl and Smetana 2003-2007), Global Biodiversity Information Facility (GBIF: http://www.gbif.org), and Beetles and Rock Art in Libya (http://jcringenbach. free.fr). The general distribution (zoogeography) of each species is also indicated as a letter code (see "Abbreviations") corresponding to main zoogeographic regions of the world proposed by Holt et al. (2013) (Fig. 2). The KSA distribution of each species is indicated (abbreviated as two letters for the Saudi provinces) (Fig. 1a). The KSA distributional records are based mainly on published records in the series "Fauna of Saudi Arabia", being published as part of the "Fauna of Arabia (Wittmer and Buttiker 1979-to date) and other available papers on Saudi beetles. The absence of a geographic entry after a species name indicates that the species was recorded from Arabia or KSA but no locality was specified. For each species the following information is given: local abundance (all values of collected specimens were log transformed and then they classified into five categories using equal interval classification: very rare: $<5$ individuals, rare: 5-17, frequent: 18-70, common: 71-300, and abundant: > 300); collecting method (see abbreviation in "Beetle collection" above); and months of collection (Roman numerals) within RKNP.

\section{Abbreviations for the zoogeographical regions}

$\begin{array}{ll}\text { AFR } & \text { Afrotropical } \\ \text { AUS } & \text { Australian } \\ \text { COS } & \text { Cosmopolitan }\end{array}$




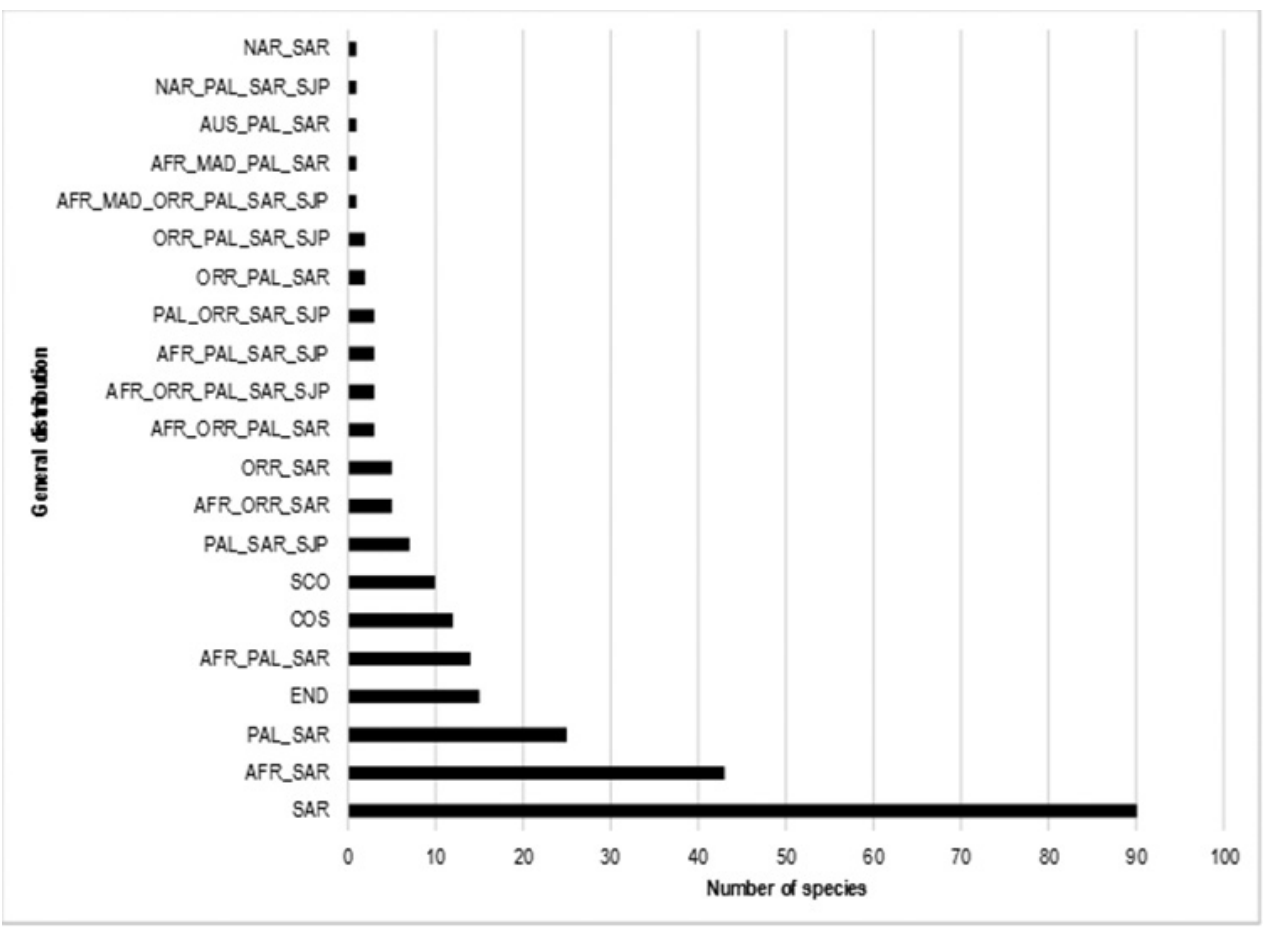

Figure 2. The general distributions frequency of the beetle fauna of Rawdhat Khorim National Park, Central Kingdom of Saudi Arabia.

MAD Madagascan

NAR Nearctic

NTR Neotropical

OCN Oceanic

ORR Oriental

PAL Palaearctic

SAR Saharo_Arabian

SCO Subcosmopolitan

SJP Sino_Japanese

\section{Results and discussion}

This study represents the first inventory of beetles in RKNP, within arid region of central KSA. In total, 15,658 specimens were collected and identified to 262 species belonging to 182 genera included in 83 subfamilies and 35 families. Forty percent of known faunal diversity is accounted for by three beetle families, Tenebrionidae ( 45 spp.), Scarabaeidae (34 spp.) and Carabidae (27 spp.) (Table 1). The families with the greatest abundant were Scarabaeidae (36.6\%) followed by Tenebrionidae (16.7\%) 
Table I. The taxonomical and faunistic analysis of the beetle fauna in Rawdhat Khorim National Park, Central Kingdom of Saudi Arabia.

\begin{tabular}{|c|c|c|c|c|c|}
\hline Family & Subfamily & Genera & Species & New record & Relative abundance \\
\hline Anthicidae & 2 & 5 & 7 & 1 & 0.27 \\
\hline Bolboceratidae & 1 & 1 & 1 & 0 & 0.01 \\
\hline Bostrichidae & 2 & 3 & 3 & 1 & 1.30 \\
\hline Brentidae & 2 & 2 & 2 & 0 & 1.10 \\
\hline Buprestidae & 5 & 7 & 10 & 0 & 1.30 \\
\hline Carabidae & 8 & 22 & 27 & 8 & 5.36 \\
\hline Cerambycidae & 2 & 2 & 2 & 0 & 0.11 \\
\hline Chrysomelidae & 5 & 8 & 8 & 1 & 3.95 \\
\hline Cleridae & 2 & 4 & 4 & 0 & 0.51 \\
\hline Coccinellidae & 1 & 8 & 15 & 0 & 3.44 \\
\hline Cryptophagidae & 2 & 2 & 2 & 1 & 0.14 \\
\hline Curculionidae & 4 & 15 & 20 & 0 & 1.99 \\
\hline Dascillidae & 1 & 1 & 1 & 0 & 8.02 \\
\hline Dermestidae & 4 & 6 & 15 & 5 & 1.58 \\
\hline Dytiscidae & 2 & 3 & 3 & 0 & 0.56 \\
\hline Elateridae & 2 & 8 & 13 & 2 & 9.30 \\
\hline Glaresidae & 0 & 1 & 2 & 0 & 0.02 \\
\hline Heteroceridae & 1 & 1 & 2 & 2 & 0.08 \\
\hline Histeridae & 3 & 8 & 14 & 0 & 0.54 \\
\hline Hybosoridae & 1 & 1 & 1 & 0 & 3.48 \\
\hline Hydrophilidae & 1 & 1 & 1 & 1 & 0.04 \\
\hline Laemophloeidae & 1 & 1 & 1 & 1 & 0.01 \\
\hline Leiodidae & 1 & 1 & 1 & 1 & 0.01 \\
\hline Meloidae & 2 & 2 & 4 & 0 & 0.17 \\
\hline Melyridae & 2 & 3 & 4 & 1 & 1.23 \\
\hline Mycetophagidae & 1 & 1 & 1 & 0 & 0.02 \\
\hline Nitidulidae & 3 & 3 & 3 & 0 & 0.70 \\
\hline Oedemeridae & 1 & 1 & 1 & 0 & 0.03 \\
\hline Phalacridae & 1 & 1 & 1 & 0 & 0.17 \\
\hline Ptinidae & 2 & 2 & 3 & 2 & 0.06 \\
\hline Scarabaeidae & 7 & 18 & 34 & 3 & 36.62 \\
\hline Scraptiidae & 1 & 1 & 2 & 0 & 0.47 \\
\hline Staphylinidae & 5 & 7 & 8 & 4 & 0.66 \\
\hline Tenebrionidae & 4 & 31 & 45 & 4 & 16.71 \\
\hline Thanerocleridae & 1 & 1 & 1 & 0 & 0.03 \\
\hline Total 35 & 83 & 182 & 262 & 38 & \\
\hline
\end{tabular}

(Table 1). Thirty-eight species have not been previously reported from KSA are listed, including 25 new records for the Arabian Peninsula. Ten families were represented by single species in the RKNP.

Eleven species (4.2\%) are classified as abundant species, from which Aphodius ictericus ghardimaouensis (Scarabaeidae) (1,238 specimens) and Karumia inaequalis 
(Dascillidae) (1,262 specimens) were the highest abundant species. Thirty-six (13.7\%) and $46(17.6 \%)$ species are concidered as common and frequent, respectively. While, $64.5 \%$ of the species considered as rare (55 spp.) or very rare (114 spp.).

The RKNP beetle fauna demonstrated variable zoogeographical affinities (Figure 2), 15 species $(6.1 \%)$ are endemic to KSA. The remainder of the species showed high affinities to SAR (36.4\%), AFR_SAR (17.4\%), and PAL_SAR (10.5\%).

This work has confirmed the occurrence of four species in KSA previously reported as occurring in "Arabia": Pseudoathyreus flavohirtus (Bolboceratidae) (Paulian, 1980); Saprinus figuratus (Histeridae) (Penati \& Vienna, 2006); Sphenoptera gahani (Buprestidae) (Kerremans 1913); and Syntomus lateralis (Carabidae) (Schatzmayr 1936). The holotypes of three species originated from RKNP: Boromorphus saudicus Schawaller, Al Dhafer \& Fadl, 2013; Dicronychus latifahae Al Dhafer \& Platia, 2013 and Reichardtiolus aldhaferi Lackner, 2014.

In particular, Adelostoma subtile arabicum and A. subtile sabulosum, described from KSA by Kaszab (1981), but the characters for the differentiation of the two subspecies and the nominate $A$. subtile subtile Reitter that proposed by Kaszab (1981) are not useful for separation, and accordingly, this taxon is treated here as A. subtile.

It is expected that the results of this study of the beetle fauna of RKNP will be used for future studies related to long-term monitoring of the beetle fauna for evaluating impacts of increased use by the growing population of nearby Riyadh and impact of climate change (Bale et al. 2002).

\section{List of species}

Suborder: Adephaga

Carabidae

Subfamily: Cicindelinae

Myriochila melancholica (Fabricius, 1798)

World distribution. Africa: AO, BF, BJ, BW, CD, CF, CG, CI, CM, CV, ER, ET, GH, GM, GN, GQ, GW, KE, MG, MS, MW, MZ, NA, NG, SD, SL, SN, SO, TD, TO, TZ, ZA, ZM, ZW. Asia: AE, AF, AZ, BH, CN, CY, EG (Sinai), IL, IN, IQ, IR, JO, KG, KW, KZ, LB, NP, OM, PK, QA, SA, SY, TJ, TM, TR, UZ, YE. Europe: AL, AM, ES, FR, GE, GR, IT, MT, NO (Svalbard), PT. North Africa: DZ, EG, ES (Canary Island), LY, MA, TN.

General distribution. AFR_MAD_ORR_PAL_SAR_SJP.

Local distribution. AS, NJ (Britton 1948; Cassola and Schneider 1997)

Collecting month and method. A very rare species. The adults were collected by LT during V-VI. 


\section{Subfamily: Carabinae}

Calosoma imbricatum Klug, 1832

World distribution. Africa: DJ, SD, TD (Britton 1948). Asia: AE, QA, SA, YE. North Africa: EG. Widespread all over Africa, the Arabian Peninsula and south Asia (Felix 2009).

General distribution. AFR_ORR_SAR.

Local distribution. AS, MK (Britton 1948), BA (El-Hawagry et al. 2013), EP, JZ, RI (Heinertz 1979).

Collecting month and method. A very rare species collected only by LT through III-IV.

\section{Calosoma olivieri Dejean, 1831}

World distribution. Asia: AE (Felix 2009), AZ, IQ, IR, JO, PK, SA, SY, TM, UZ. Europe: MT, PT (Azores). North Africa: DZ, EG, ES (Canary Island), LY, MA, TN.

General distribution. PAL_SAR.

Local distribution. MK (Britton 1948), RI (Heinertz 1979).

Collecting month and method. Very rare species. The beetles were collected by HP, and by PT under canopy of $R$. stricta in II.

Subfamily: Scaritinae

Distichus planus (Bonelli, 1813)

World distribution. Asia: AZ, IQ, IR, JO, KZ, PK, SA, SY, TJ, TM, UZ, YE. Europe: ES, FR, GE, GR, IT, MT, PT. North Africa: EG, MA, TU.

General distribution. PAL_SAR.

Local distribution. RI (Balkenohl 1994).

Collecting month and method. A frequent species that was collected HP, LT and PT during II, IV-VI, VIII, X, and XII.

Dyschirius beludscha ganglbaueri Znojko, 1927

World distribution. Asia: AE (Felix 2009), AF, EG (Sinai), IL, IQ, IR, KZ, MN, PK, SY, TJ, TM. North Africa: DZ, EG, MA, TU. New to KSA.

General distribution. PAL_SAR.

Collecting month and method. Very rare species that was collected by LT during IV. 
Scarites procerus eurytus Fischer von Waldheim, 1828

World distribution. Asia: AF, IQ, IR, KG, KW, KZ, PK, SA, SY, TM, TR, UZ. Europe: ES, GE, GR, IT, PT, RU. North Africa: DZ, EG, LY, MA, TN.

General distribution. PAL_SAR.

Local distribution. EP, QS, RI (Balkenohl 1994), MK (Beccari 1971).

Collecting month and method. Very rare species. The adults were collected by $\mathrm{HP}$ and PT during V.

\section{Subfamily: Siagoninae}

Siagona europaea Dejean, 1826

World distribution. Asia: AF, CY, EG (Sinai), IL, IN, IQ, IR, JO, KZ, LB, PK, SA, SY, TJ, TM, TR, UZ, YE. Europe: AL, AM, AZ, BG, ES, GE, GR, HR, IT, MK, PT, RU.

General distribution. ORR_PAL_SAR.

Local distribution. MK (Britton 1948), RI (Al Dhafer et al. 2016).

Collecting month and method. A rare species. The beetles were collected by HP, LT and PT through IV-V, VII and XII.

Subfamily: Melaeninae

Cymbionotum pictulum (Bates, 1874)

World distribution. Africa: SD. Asia: Af, IQ, IR, KZ, SA, TM, TR. E: RU.

General distribution. AFR_PAL_SAR.

Local distribution. MK (Britton 1948; Ball and Shpeley 2005), RI (Al Dhafer et al. 2016).

Collecting month and method. Frequent species that was collected by HP and LT during II-V and XII. HP.

Cymbionotum semelederi (Chaudoir, 1864)

World distribution. Africa: MR, NE, SD, SO, TD. Asia: AE (Felix 2009), AF, AZ, CY, IQ, IR, JO, KW, KZ, PK, SA, SY, TM, TR, UZ, YE. Europe: AM, GE, RU. North Africa: DZ, EG, MA, TN.

General distribution. AFR_PAL_SAR.

Local distribution. EP, RI (Basilewsky 1979), MK (Britton 1948).

Collecting month and method. Frequent species. It was collected by LT and PT during II-V and XII. 


\section{Subfamily: Trechinae}

Bembidion wittmeri (Basilewsky, 1979)

World distribution. Asia: SA.

General distribution. END.

Local distribution. RI (Basilewsky 1979).

Collecting month and method. Common species. Its specimens were collected by HP, LT and PT through I-V and XII.

\section{Tachyura lucasi (Jacquelin du Val, 1852)}

World distribution. Africa: CD, CF, CM, ET, GQ, NG, ZA. Asia: CY, IL, IR, LB, SY, TR. Europe: ES, IT, PT. North Africa: DZ, EG, MA, TN. New to Arabian Peninsula.

General distribution. AFR_MAD_PAL_SAR.

Collecting month and method. A rare species. The beetles were collected by LT through IV-V and VII.

\section{Subfamily: Brachininae}

Brachinus crepitans (Linné, 1758)

World distribution. Asia: AZ, CY, IQ, IR, KG, KZ, SY, TJ, TM, TR, UZ. Europe: AL, AM, AT, BA, BE, BG, BY, CH, CZ, DE, DK, EE, ES, FI, FR, GB, GE, GR, HR, HU, IE, IT, LT, LU, LV, MD, NL, NO, PL, PT, RO, RS, RU, SE, SI, SK, UA. New to Arabian Peninsula.

General distribution. PAL_SAR.

Collecting month and method. Rare species. It was collected by HP during IV and XII; and by LT during V.

\section{Brachinus nobilis Dejean, 1831}

World distribution. Asia: IL, IQ, IR, SA, SY, TR, YE. North Africa: DZ, MA, TN. General distribution. SAR.

Local distribution. MK (Britton 1948), RI (Basilewsky 1979).

Collecting month and method. Rare species. The adults were collected by HP under debris and stones around temporary fresh water pool during XII. 


\section{Subfamily: Harpalinae}

Amara aulica (Panzer, 1796)

World distribution. Asia: AZ, CN, KG, KZ, MN, RU, TJ, TM, TR, UZ. Europe: AL, AM, AT, BA, BE, BG, BY, CH, CZ, DE, DK, EE, ES, FI, FO, FR, GB, GE, GR, HR, HU, IE, IT, LI, LT, LV, MD, MK, NL, NO, PL, RO, RS, RU, SK, SE, SI, UA. North Africa: ES (Canary Island). New to Arabian Peninsula.

General distribution. PAL_SAR_SJP.

Collecting month and method. A frequent species that was collected HP and PT through I-IV and XII.

\section{Amara maindroni Bedel, 1907}

World distribution. Asia: AE (Felix 2009), AF, IQ, IR, JO, PK, SA, SY. North Africa: $\mathrm{DZ}, \mathrm{MA}, \mathrm{TN}$.

General distribution. SAR.

Local distribution. RI (Hieke 1993).

Collecting month and method. Very rare species. The adult was very rare and collected by Lt in XI.

Anthia duodecimguttata Bonelli, 1813

World distribution. Asia: AE (Felix 2009), IQ, IR, JO, KW, OM, QA, SA, YE. North Africa: EG.

General distribution. SAR.

Local distribution. AS, JZ, MK, RI (Britton 1948; Beccari 1971; Heinertz 1979).

Collecting month and method. Very rare species. The adult beetles were collected by HP and LT at sandy area during IV.

Calodromius mayeti (Bedel, 1907)

World distribution. Asia: AE (Felix 2009), IR, SA. North Africa: MA, TN.

General distribution. SAR.

Local distribution. MD (Mateu 1986).

Collecting month and method. Very rare species that was collected by HP under stones in IV. 
Chlaenius flavipes Menetries, 1832

World distribution. Asia: AF, AZ, IQ, IR, KG, KZ, TJ, TM, TR, UZ. Europe: AL, AM, BA, BG, GE, GR, HR, HU, MD, MK, RO, RS, RU, UA. New to Arabian Peninsula.

General distribution. PAL_SAR.

Collecting month and method. Very rare species that was collected by HP under plant debris during XII.

Harpalus affinis (Schrank, 1781)

World distribution. Asia: AZ, CN, CY, IL, IR, KG, KP, KZ, MN, TR. Australia: AU, NZ. Europe: AD, AL, AM, AT, BA, BE, BG, BY, CH, CZ, DE, DK, EE, ES, FI, FR, GB, GE, GR, HR, HU, IE, IT, LI, LT, LU, LV, MD, MK, NL, NO, PL, PT, RO, RS, RU, SE, SI, SK, UA. North America: CA, US. New to Arabian Peninsula.

General distribution. SCO.

Collecting month and method. A rare species. The specimens were collected by HP under stones and plant debris during II, IV and XII.

Merizomena buettikeri (Mateu, 1986)

World distribution. Asia: SA.

General distribution. END.

Local distribution. MD (Mateu 1986).

Collecting month and method. Very rare species. It was collected by LT in IV and VI.

Microlestes discoidalis (Fairmaire, 1892)

World distribution. Africa: ER, KE, MR, NE, SD, SO, TD. Asia: AE, AF, IL, IN, IR, SA, TR, YE.

General distribution. AFR_ORR_SAR.

Local distribution. MK (Britton 1948; Mateu 1979).

Collecting month and method. Very rare species that was collected by LT through V.

Orthotrichus cymindoides (Dejean, 1831)

World distribution. Asia: AF, CN, IN, SY. North Africa: EG. New to Arabian Peninsula. 
General distribution. ORR_PAL_SAR_SJP.

Collecting month and method. Frequent species. The adults were collected by HP, LT and PT during I-V, IX and XII.

Platytarus faminii faminii (Dejean, 1826)

World distribution. Africa: CV. Asia: AE (Felix 2009), AZ, CY, IL, IQ, KG, KZ, SA, SY, TM, TR, UZ, YE (Socotra). Europe: AM, ES, FR GR, IT, PT. North Africa: DZ, EG, ES (Canary Islands), LY, MA, TN.

General distribution. AFR_PAL_SAR.

Local distribution. AS, EP, RI (Mateu 1986).

Collecting month and method. Very rare species that was collected by LT in III.

Poecilus wollastoni (Wollaston, 1854)

World distribution. Asia: IQ, KW, SA, YE. North Africa: DZ, EG, ES (Canary Islands), LY, MA, PT (Madeira Archipelago), TN.

General distribution. SAR.

Local distribution. It was recorded from Arabia without exact locality by Emden (1954) and a recent occurrence in KSA has been confirmed by Al Dhafer et al. (2016).

Collecting month and method. Frequent species, which was collected by HP, LT and PT during I-II, IV-VI and XI-XII.

Stenolophus marginatus Dejean, 1829

World distribution. Asia: AE (Felix 2009), AF, AZ, CY, IL, IQ, IR, JO, KW, KZ, SA, SY, TJ, TM, TR, UZ. Europe: AL, AM, BA, BG, ES, FR, GE, GR, HR, IT, MK, PT, RS, UA. North Africa: DZ, EG, ES (Canary Islands), MA, PT (Madeira Archipelago), TN.

General distribution. PAL_SAR.

Local distribution. EP, RI (Basilewsky 1979).

Collecting month and method. Frequent species. The beetles were collected by LT in IV-V, VII and IX.

Stenolophus pseudoobockianus Felix \& Muilwijk, 2009

World distribution. Asia: AE (Felix 2009). New to KSA.

General distribution. SAR.

Collecting month and method. Very rare species that was collected by LT during IV. 


\section{Syntomus lateralis (Motschulsky, 1855)}

World distribution. Asia: AE (Felix 2009), IL, IQ, IR, SA, SY. North Africa: DZ, EG, ES (Canary Islands), LY, MA, TN.

Local distribution. Schatzmar (1936) mentioned Arabia among the distribution of this species in his work on Carabidae of Egypt, without given any further detailed about the locality.

General distribution. SAR.

Collecting month and method. Common species that was collected by HP, LT and PT in I-XII.

Dytiscidae

Subfamily: Dytiscinae

Eretes sticticus (Linné, 1767)

World distribution. Africa: BW, KE, MG, NA, SD, ZA, ZW. Asia: AE, AZ, BT, CN, CY, EG (Sinai), IN, IQ, IR, JA, á, KW, NP, OM, PK, SA, SY, TM, TR, TW, YE. Europe: AM, BA, BG, ES, FR, GE, GR, HR, HU, IT, PT, RU, SI, UA, RS. North Africa: DZ, EG, ES (Canary Islands), LY, MA, PT (Madeira Archipelago), TN. North America: MX, PR, US. South America: EC, PE, VE.

General distribution. COS.

Local distribution. AS, EP, MD, RI (Brancucci 1979 1984).

Collecting month and method. A frequent species. The adult beetles were collected by LT in IV-VI.

\section{Subfamily: Hydroporinae}

Hydroglyphus signatellus (Klug, 1834)

World distribution. Africa: ET, KE, SD, SN. Asia: AE (Hájek and Brancucci 2011), AZ, CY, EG (Sinai), IL, IQ, IR, JO, KW, KZ, PK, SA, SY, TJ, TM, TR, UZ, YE. Europe: AM, BA, ES, GE, GR, HR, IT, RS, RU. North Africa: DZ, EG, LY, MA, TN.

General distribution. AFR_PAL_SAR.

Local distribution. EP, RI (Brancucci 1979 1984).

Collecting month and method. Very rare species that was collected by LT during V.

Hygrotus inscriptus (Sharp, 1882)

World distribution. Asia: AE, IQ, IR, KW, SA, SY, TM, UZ. North Africa: EG. The distribution is updated from Hájek and Brancucci (2011). 
General distribution. SAR.

Local distribution. EP (Brancucci 1984).

Collecting month and method. Frequent species that was collected by LT in VI.

\section{Suborder: Polyphaga}

Hydrophilidae

Subfamily: Hydrophilinae

Hydrochara flavipalpis (Boheman, 1851)

World distribution. Asia: OM, YE. New to KSA.

General distribution. SAR.

Collecting month and method. A rare species, which was collected by HP during $\mathrm{V}$ and XII.

\section{Histeridae}

Subfamily: Abraeinae

Teretrius pulex Fairmaire, 1877

World distribution. Africa: MR, NE, SN. Asia: AE (Kanaar 2007), OM, SA, SY. North Africa: DZ, EG, TN.

General distribution. AFR_SAR.

Local distribution. EP (Mazur 1994; Penati and Vienna 2006).

Collecting month and method. Very rare species that was collected by BV on branches of $Z$. nummularia during $\mathrm{V}$.

\section{Subfamily: Sapriniae}

\section{Pholioxenus sp.1}

Collecting month and method. A rare species. The specimens were collected by PT under canopy of $A$. ehrenbergiana, $A$. gerrardii and $R$. stricta during IV-V and X.

\section{Pholioxenus sp.2}

Collecting month and method. Frequent species. The beetles were collected by PT under canopies of $A$. ehrenbergiana, A. gerrardii, C. procera, L. shawii, $R$. stricta and Z. nummularia; and by LT through V-XI. 


\section{Reichardtiolus aldhaferi Lackner, 2014}

World distribution. Asia: SA (Lackner 2014).

General distribution. END.

Local distribution. RI (Lackner 2014).

Collecting month and method. A rare species. The beetles were collected by HP and LT during I-II and XII.

Saprinus chalcites (Illiger, 1807)

World distribution. Africa: AO, BF, ET, GM, KE, ML, MR, NA, SD, SN, SO, TZ. Asia: AE, AF, CY, ID, IL, IN, IQ, IR, JO, KW, KZ, MM, MN, OM, PK, SA, TR, YE. Australia: AU. Europe: ES, FR, GR, IT, MT, PT, RU. North Africa: DZ, EG, ES (Canary Islands), LY, MA, PT (Madeira Archipelago), TN. South America: AR.

General distribution. SCO (Penati and Vienna 2006).

Local distribution. AS, BA, JZ, MK, NJ, RI (Kryzhanovskij 1979; Mazur 1994; Penati and Vienna 2006).

Collecting month and method. Very rare species. The adults were collected by PT under canopies of A. ehrenbergiana, L. shawii and Z. nummularia during IV and VII.

Saprinus confalonierii G. Müller, 1933

World distribution. Africa: MR. Asia: AE (Kanaar 2007), OM, SA. North Africa: DZ, EG, LY, TN.

General distribution. AFR_SAR.

Local distribution. AS, EP, HA, NB, NJ, RI (Mazur 1994; Penati and Vienna 2006). Collecting month and method. Very rare species that was collected by LT in X.

Saprinus figuratus Marseul, 1855

World distribution. Asia: IL, JO, SA, SY. North Africa: DZ, EG, ES (Canary Islands), LY, MA, TN.

General distribution. SAR.

Local distribution. just recorded from Arabia (Penati and Vienna 2006).

Collecting month and method. Very rare species that was collected by HP during II. 
Saprinus moyses Marseul, 1862

World distribution. Asia: IR, KW, SA, SY, TR. Europe: GR. North Africa: DZ, EG, ES (Canary Islands), LY, MA, TN.

General distribution. PAL_SAR.

Local distribution. HA (Mazur 1994; Penati and Vienna 2006).

Collecting month and method. Very rare species. The beetles were collected by BT and LT during V, VII and X.

Saprinus muelleri Mazur, 1997

World distribution. Asia: AE (Kanaar 2007), AF, PK, SA.

General distribution. SAR.

Local distribution. EP, MK, RI (Penati and Vienna 2006).

Collecting month and method. Very rare species that was collected by LT during I-II.

\section{Saprinus sp.}

Collecting month and method. A rare species. The adults were collected by LT during V-VI and X.

Xenonychus tridens (Jacquelin Duval, 1853)

World distribution. Africa: CV, MR, NG, TD. Asia: AE (Kanaar 2007), CY, IL, OM, SA, SY, TR.

Europe: ES, FR, GR, IT, PT. North Africa: DZ, EG, ES (Canary Islands), LY, MA, TN.

General distribution. AFR_PAL_SAR.

Local distribution. EP, MK (Mazur 1994; Penati and Vienna 2006), RI (Al Dhafer et al. 2016).

Collecting month and method. Very rare species that was recorded by PT under canopy of $A$. ehrenbergiana during IV.

Xenophilothis choumovitchi (Thérond \& Hollande, 1965)

World distribution. Asia: AE (Kanaar 2007), OM, SA. North Africa: DZ.

General distribution. SAR.

Local distribution. EP, RI (Penati and Vienna 2006).

Collecting month and method. Very rare species, which was collected by LT in V. 


\section{Zorius sp.}

Collecting month and method. A rare species. The adults were collected by PT under canopies of $A$. gerrardii, C. procera, L. shawii and $R$. stricta during III-IV.

\section{Subfamily: Histerinae}

Atholus bimaculatus (Linnaeus, 1758)

World distribution. Africa: BF, CF, CM, DJ, KE, MR, SN, TD. Asia: AE (Kanaar 2007), AF, CN, CY, IL, IN, IQ, IR, JO, JP, KG, KP, KR, KZ, MM, OM, RU, SA, SY, TJ, TM, UZ, YE. Europe: AL, AM, AT, BA, BE, BG, BY, CH, CZ, DE, DK, EE, ES, FI, FR, GB, GE, GR, HR, HU, IE, IT, LI, LV, NL, NO, PL, PT, RO, RS, RU, SE, SI, SK, UA. North Africa: DZ, ES (Canary Islands), LY, MA, TN. North America: CA, US. South America: AR, BR, CL.

General distribution. SCO (Penati and Vienna 2006).

Local distribution. AS (Kryzhanovskij 1979), RI (Al Dhafer et al. 2016).

Collecting month and method. Very rare species that was collected by PT under canopy of A. ehrenbergiana during IV.

\section{Leiodidae}

Subfamily: Leiodinae

Chobautiella anisotomoides (Fairmaire, 1876)

World distribution. Asia: AE (Švec 2010a). North Africa: DZ, ES (Canary Islands), MA, TN (Švec 2010). New to KSA.

General distribution. SAR.

Collecting month and method. Very rare species. The specimens were collected by LT in XII.

\section{Staphylinidae}

Subfamily: Pselaphinae

Ctenisomorphus major (Raffray, 1877)

World distribution. Africa: ET. Asia: AE (Besuchet and Cuccodoro 2011), EG (Sinai), IL, IR, JO, SA, TR, YE. North Africa: DZ, EG, TN.

General distribution. AFR_SAR.

Local distribution. AS, BA, EP, MD, RI (Besuchet 1981). 
Collecting month and method. Very rare species that was collected by LT in IV-V and VII.

Enoptostomus arabicus Besuchet \& Cuccodoro, 2011

World distribution. Asia: AE (Besuchet and Cuccodoro 2011). New to KSA.

General distribution. SAR.

Collecting month and method. Very rare species, which was collected by LT during VII.

\section{Subfamily: Tachyporinae}

Sepedophilus sp.

Collecting month and method. Very rare species. It was collected by PT under canopy of $Z$. nummularia in III.

\section{Subfamily: Aleocharinae}

Atheta atramentaria (Gyllenhal, 1810)

World distribution. Africa: MR, ZA. Asia: AZ, CN, CY, IN, IR, JP, KP, KZ, NP, PK, RU, TR. Europe: AL, AT, BE, BG, CH, CZ, DE, DK, EE, ES, FI, FO, FR, GB, GE, GR, HU, IE, IS, IT, LT, LU, NL, NO, PL, PT, RU, SE, SK. North Africa: DZ, EG, ES (Canary Islands), MA, PT (Madeira Archipelago), TN. New to Arabian Peninsula.

General distribution. AFR_PAL_ORR_SAR_SJP.

Collecting month and method. Rare species. The specimens of this species were collected by PT under canopies of A. ehrenbergiana, A. gerrardii, L. shawii, R. stricta, and $Z$. nummularia in I-II and X-XI; and by SW on branches of $C$. procera through VII.

\section{Subfamily: Oxytelinae}

Bledius niloticus Erichson, 1840

World distribution. Africa: AO, ET, SN, ZA. Asia: CN, IL, IN, JP, KP, KR, LB, LK, SA (Beccari 1971), SY. North Africa: DZ, EG, MA, TN.

General distribution. AFR_ORR_PAL_SAR_SJP. 
Local distribution. RI (Beccari 1971).

Collecting month and method. Very rare species that was collected by LT during X.

Carpelimus pusillus (Gravenhorst, 1802)

World distribution. Asia: CY, IR, KZ, RU, TR. Australia: AU. Europe: AL, AM, AT, BA, BE, BG, CH, CZ, DE, DK, EE, ES, FI, FR, GB, GE, GR, HR, HU, IE, IS, IT, LT, LV, NL, NO, PL, PT, RO, RU, SE, SI, SK, UA. North Africa: DZ, EG, ES (Canary Islands), PT (Madeira Archipelago). North America: US. New to Arabian Peninsula.

General distribution. SCO.

Collecting month and method. Very rare species, which was collected by LT through XII.

\section{Carpelimus sp.}

Collecting month and method. Very rare species that was collected by LT in VII.

Subfamily: Paederinae

Philonthus sp.

Collecting month and method. Very rare species that was collected by LT through VI.

\section{Glaresidae}

Glaresis arabica (Paulian, 1980)

World distribution. Asia: OM, SA.

General distribution. SAR.

Local distribution. EP, RI (Paulian 1980).

Collecting month and method. Very rare species that was collected by LT during V.

\section{Glaresis sp.}

Collecting month and method. Very rare species that was collected by LT in IV. 


\section{Bolboceratidae}

Subfamily: Bolboceratinae

Pseudoathyreus flavohirtus (Wlaker, 1871)

World distribution. Asia: Arabia

General distribution. SAR.

Local distribution. Paulian (1980) recorded this species from Arabia without exact locality.

Collecting month and method. Very rare species that was collected by LT in IV.

Hybosoridae

Subfamily: Hybosorinae

Hybosorus illigeri Reiche, 1853

World distribution. Africa: KM, MG, UG. Asia: AF, AZ, CN, CY, EG (Sinai), IL, IN, IQ, IR, JO, PK, SA, SY, TJ, TM, TR, UZ, YE, VN. Europe: AM, BG, ES, FR, GE, GR, HR, IT, MK, PT, RO, RS, RU, UA. North Africa: DZ, EG, LY, MA, TN. North America: CU, HT, MX, NI, US. South America: VE.

General distribution. SCO.

Local distribution. EP, MD, MK, NJ, RI (Beccari 1971, Kuijten 1980).

Collecting month and method. An abundant species. The adult beetles were collected by HP, LT and PT through II, IV-VIII.

Scarabaeidae

Subfamily Eremazinae

Eremazus giganteus Král, 2015

World distribution. Asia: AE (Král and Batelka 2015). New to KSA.

General distribution. SAR.

Collecting month and method. Very rare species that collected by LT during V.

Eremazus unistriatus Mulsant, 1851

World distribution. Africa: NE, SD. Asia: AE, AF, IL, IN, IQ, IR, KZ, PK, SA, TJ, TM, TR, UZ. Europe: AM, GE. North Africa: DZ, EG, ES (Canary Islands), LY, $\mathrm{MA}, \mathrm{TN}$.

General distribution. AFR_ORR_PAL_SAR.

Local distribution. EP, HA, MD, MK, QS, RI (Pittino 1984). 
Collecting month and method. A frequent species. The adults of this species were collected by PT under canopy of $A$. ehrenbergiana, and by HP and LT during I-II, IV-VII and IX.

\section{Subfamily: Aphodiinae}

Aphodius adustus Klug, 1855

World distribution. Africa: CD, CM, DJ (Pittino 1984), GW, KE, MZ, NA, SD (Balthasar 1972), SN, TD, TZ. Asia: SA, YE.

General distribution. AFR_SAR.

Local distribution. The species was reported from Arabia without exact locality (Pittino 1984) and recently its occurrence in KSA: RI has been confirmed by AbdelDayem et al. (2016).

Collecting month and method. Very rare species that was collected by LT during IV.

\section{Aphodius arabicus Harold, 1875}

World distribution. Asia: EG (Sinai), IL, IR, KW, SA, YE. North Africa: EG

General distribution. SAR.

Local distribution. EP, JZ, MD, MK, RI (Pittino 1984).

Collecting month and method. Common species that was collected by LT through V-VII and IX-X.

Aphodius beluchistanicus Petrovitz, 1962

World distribution. Asia: IQ, IR, SA.

General distribution. SAR.

Local distribution. EP, RI (Pittino 1984).

Collecting month and method. A rare species, which was collected by LT in I and XII.

Aphodius chobauti Clouët, 1896

World distribution. Asia: IL, IQ, IR, JO, SA. North Africa: DZ, EG, LY, MA, TN. General distribution. SAR.

Local distribution. MD, QS, RI (Pittino 1984).

Collecting month and method. Rare species. The specimens were collected by $\mathrm{BV}$ on branches of $A$. gerrardii, and by HP and LT during IV-V and XI. 
Aphodius ictericus ghardimaouensis Balthasar, 1929

World distribution. Asia: CY, IL, IR, JO, LB, SA, SY, TR. Europe: ES, FR, GR, HR, IT, MT, PT. North Africa: DZ, EG, ES (Canary Islands), LY, MA, TN.

General distribution. PAL_SAR.

Local distribution. EP (Pittino 1984).

Collecting month and method. Abundant species that was collected by LT during I, III and IX.

\section{Aphodius lividus (Olivier, 1789)}

World distribution. Africa: MG, NA. Asia: CN, CY, EG (Sinai), IL, IR, KG, KW, KZ, LB, MN, NP, OM, SA, SY, TJ, TM, TR, TW, UZ. Australia: AU, NZ, PG. Europe: AL, AM, AT, BA, BE, BY, CH, CZ, DE, EE, ES, FI, FR, GB, GE, GR, HR, HU, IT, LT, LV, MK, MT, NL, PL, PT, RO, RS, RU, SE, SI, SK, UA. North Africa: DZ, EG, ES (Canary Islands), LY, MA, PT ((Madeira Archipelago), TN. North America: CU, GT, MX, NI, PA, US.

General distribution. SOC.

Local distribution. AS, BA, EP, JZ, MD, MK, QS, RI (Beccari 1971, Pittino 1984; El-Hawagry et al. 2013).

Collecting month and method. Common species. The beetles were collected by LT through IV-VII and IX-XII.

Aphodius luridus (Fabricus, 1775)

World distribution. Asia: CN, CY, IL, IR, KG, KZ, RU, SA, SY, TJ, TM, TR. Europe: $\mathrm{AL}, \mathrm{AM}, \mathrm{AT}, \mathrm{BA}, \mathrm{BE}, \mathrm{BG}, \mathrm{BY}, \mathrm{CH}, \mathrm{DE}, \mathrm{DK}, \mathrm{EE}, \mathrm{ES}, \mathrm{FI}, \mathrm{FR}, \mathrm{GB}, \mathrm{GE}, \mathrm{GR}$, HR, HU, IE, IT, LT, LV, MK, NL, NO, PL, PT, RO, RS, RU, SE, SI, SK, TR, UA. North Africa: MA, TN.

General distribution. PAL_SAR_SJP.

Local distribution. RI (Abdel-Dayem et al. 2016).

Collecting month and method. Very rare species that was collected by LT in I and X.

Aphodius pruinosus Reitter, 1892

World distribution. Africa: MR. Asia: AF, IL, IQ, IR, KG, KW, KZ, LB, OM, PK, SA, TJ, TM, TR, UZ. Europe: RU. North Africa: DZ, EG, LY, MA, TN.

General distribution. AFR_PAL_SAR.

Local distribution. BA, EP, HA, JZ, MD, MK, QS, RI (Pittino 1984). 
Collecting month and method. An abundant species. The adults were collected by PT by PT under canopies of $L$. shawii and $R$. stricta; and by LT through II-VI and IX-X.

\section{Aphodius rendallii (Wollaston, 1867)}

World distribution. Asia: IL, IQ, JO, SA. North Africa: DZ, EG, LY, MA, TN.

General distribution. SAR.

Local distribution. EP, HA, QS, RI (Pittino 1984) [under the name Aphodius opacior D. Koshantschikov 1894] (Král and Batelka 2015).

Collecting month and method. Common species. The specimens of this species were collected by PT under canopies of A. ehrenbergiana, A. gerrardii, L. shawii, $R$. stricta and $Z$. nummularia; and by LT through IV-V and IX-X.

\section{Aphodius translucidus Petrovitz, 1961}

World distribution. Asia: AF, IN, IQ, IR, OM, PK, RU, SA, TM. North Africa: EG (Pittino 1984).

General distribution. ORR_SAR.

Local distribution. EP, MD, MK, RI (Pittino 1984).

Collecting month and method. Common species that was collected by LT in IV-V and IX-XI.

\section{Aphodius wollastoni iranicus Balthasar, 1946}

World distribution. Asia: EG (Sinai), IN, IQ, IR, JO, OM, PK, SA, SY, YE.

General distribution. ORR_SAR.

Local distribution. EP, HA, MD, QS, RI (Pittino 1984).

Collecting month and method. Abundant species. It was collected by PT under canopies of A. ehrenbergiana and C. procera; and by HP and LT through I-V and XI-XII.

Granulopsammodius plicatulus (Fairmeire, 1892)

World distribution. Africa: ET, SD, SO. Asia: SA, YE. North Africa: DZ, EG, LY, MA. General distribution. AFR_SAR.

Local distribution. AS, BA, EP, MD, MK, RI (Paulian 1980; Pittino 1984; ElHawagry et al. 2013).

Collecting month and method. Common species, which was collected by PT under canopy of $Z$. nummularia; and by LT through IV-VIII. 
Leiopsammodius laevicollis (Klug, 1845)

World distribution. Africa: CG, DJ, ER, ET, SD, SO. Asia: IL, SA, SY, YE. North Africa: DZ, EG, LY, MA, TN.

General distribution. AFR_SAR.

Local distribution. BA, HA, JZ, MD, MK, RI (Pittino 1984; El-Hawagry et al. 2013).

Collecting month and method. A rare species that was collected by PT under canopy of L. shawii and R. stricta; and by LT through IV-VI, IX and XII.

Pararhyssemus coluber (Mayet, 1887)

World distribution. Africa: SO. Asia: AF, EG (Sinai), IR, SA. North Africa: DZ, EG, LY, MA, TN.

General distribution. AFR_SAR.

Local distribution. AS, BA, HA, MD, MK, RI (Pittino 1984).

Collecting month and method. Very rare species. The beetles were collected by LT in IV.

Pleurophorus arabicus (Pittino \& Mariani, 1986)

World distribution. Asia: AZ, IR, JO, SA, TM. Europe: RU.

General distribution. PAL_SAR.

Local distribution. EP, QA, RI (Pittino 1984) [under the name Pleurophorus anatolicus Petrovitz 1961] (Král and Batelka 2015).

Collecting month and method. A common species. The adult beetles were collected by PT under canopies of $A$. ehrenbergiana, A. gerrardii, C. procera and $R$. stricta; and by HP and LT through III-V and XII.

\section{Pseudomothon sp.}

Collecting month and method. Rare species that was collected by LT during IV.

Rhyssemus brevitarsis Pinttino, 1984

World distribution. Asia: SA.

General distribution. END.

Local distribution. BA, JZ, MD, MK, QS, RI (Pittino 1984; El-Hawagry et al. 2013).

Collecting month and method. Very rare species that was collected by LT during IV. 
Rhyssemus granosus (Klug \& Erichson, 1842)

World distribution. Africa: CM, CV, ET, KE, ML, MR, NE, NG, SD, SN, SO, TD, TZ. Asia: SA, YE. North Africa: EG.

General distribution. AFR_SAR.

Local distribution. AS, BA, EP, JZ, MD, MK, QS, RI (Beccari 1971, Pittino 1984; El-Hawagry et al. 2013).

Collecting month and method. A rare species. The beetles were collected by LT through IV-V, VII and X.

Rhyssemus saoudi Pittino, 1984

World distribution. Asia: SA.

General distribution. END.

Local distribution. AS, BA, JZ, MK, RI (Pittino 1984; El-Hawagry et al. 2013; Abdel-Dayem et al. 2016).

Collecting month and method. Common species. The adult beetles were collected by PT under canopies of C. procera, L. shawii, R. stricta and Z. nummularia; and by HP and LT through III-V and VII-XI.

Subfamily Scarabaeinae

Metacatharsius inermis (Laporte, 1840)

World distribution. Africa: ER, ET, GM, KE, MR, SD, SN, SO, TD. Asia: IN, IQ, IR, PK, SA. North Africa: EG.

General distribution. AFR_ORR_SAR.

Local distribution. AS, EP, RI (Paulian 1980).

Collecting month and method. Rare species, which was collected during V.

Scarabaeus bannuensis A. Janssens, I940

World distribution. Africa: MR, TD. Asia: IQ, IR, PK, SA. North Africa: DZ, LY, MA, TN.

General distribution. AFR_SAR.

Local distribution. RI (Ziani and Gudenzi 2012)

Collecting month and method. Common species. The specimens were collected by PT under canopies of $A$. ehrenbergiana, A. gerrardii, $L$ shawii and $R$. stricta; and by HP, LT, SW during III-VIII. 
Scarabaeus cristatus Fabricius, 1775

World distribution. Africa: ER, GN, MR, NE, SD, SN, TD. Asia: AE, AF, IL, IQ, IR, PK, SA. North Africa: EG, LY.

General distribution. AFR_SAR.

Local distribution. AS, EP, MK, RI (Paulian 1980).

Collecting month and method. Very rare species. The specimens were collected by HP and LT during V and VIII.

Subfamily: Dynamopodinae

Orubesa plicifrons (Fairmaire, 1897)

World distribution. Africa: ET, NE, SN. Asia: SA (Paulian 1980). North Africa: MA.

General distribution. AFR_SAR.

Local distribution. RI (Paulian 1980).

Collecting month and method. A common species. The adult beetles were collected by HP and LT in IV.

Subfamily Melolonthinae

Maladera insanabilis (Brenske, 1894)

World distribution. Asia: AE, AF, IL, IN, IQ, IR, JO, KW, NP, OM, PK, SA. North Africa: LY.

General distribution. ORR_SAR.

Local distribution. EP, RI (Ahrens 2000).

Collecting month and method. Very rare species that was collected by LT during V, VII and XI.

Schizonycha buettikeri Sabatinelli \& Pontuale, 1998

World distribution. Asia: OM, SA.

General distribution. SAR.

Local distribution. EP, HA, RI (Sabatinelli and Pontuale 1998).

Collecting month and method. A rare species that was collected by LT during IV-V. 
Schizonycha flavicornis Brenske, 1898

World distribution. Africa: SD, SO. Asia: SA, YE. North Africa: EG.

General distribution. AFR_SAR.

Local distribution. AS, BA, EP, JZ, MD, MK, RI (Sabatinelli and Pontuale 1998).

Collecting month and method. Rare species, which was collected by LT in IV and X-XI.

Sphaerotrochalus somalicola (Frey, 1960)

World distribution. Africa: ET, SO. Asia: OM, SA, YE.

General distribution. AFR_SAR.

Local distribution. AS, BA, HA, JZ, MK, RI (Ahrens 2000).

Collecting month and method. A common species. The specimens were collected by PT under canopies of $A$. ehrenbergiana, $A$. gerrardii and $R$. stricta; and by LT during I, IV-V and X-XII.

Subfamily Rutelinae

Clipadoretus habibi Král, 2015

World distribution. Asia: AE (Král and Batelka 2015). New to KSA.

General distribution. SAR.

Local distribution. RI (Beccari 1971).

Collecting month and method. A rare species that was recorded by LT in V-VII and IX.

\section{Clipadoretus sp.}

Collecting month and method. Moderately common species that was collected by LT during $V$.

Phaeadoretus syriacus (C. É. Blanchard, 1851)

World distribution. Asia: IQ, IR. New to Arabian Peninsula.

General distribution. SAR.

Collecting month and method. Abundant species. The specimens were collected by PT under canopies of $A$. ehrenbergiana, A. gerrardii, L. shawii and $Z$. nummularia; and by HP and LT through I-V. 


\section{Subfamily Dynastinae}

Pentodon algerinus dispar Baudi, 1870

World distribution. Africa: ER. Asia: CY, IL, IQ, IR, JO, KW, OM, QA, SA, SY, YE. Europe: AM, GR.

General distribution. AFR_PAL_SAR.

Local distribution. EP, MK, RI (Endrödi 1980).

Collecting month and method. Common species. The adults were collected by PT under canopies of $R$. stricta and $Z$. nummularia; and by HP and LT through IV-V and VIII-IX.

Podalgus cuniculus arabicus Fairmaire, 1895

World distribution. Asia: AE, EG (Sinai), IL, KW, OM, SA, YE. North Africa: EG. General distribution. SAR.

Local distribution. EP, MK, RI (Endrödi 1980).

Collecting month and method. A common species that was collected by HP and LT through IV-XI.

\section{Dascillidae}

Subfamily: Karumiinae

Karumia inaequalis Pic, 1929

World distribution. Asia: SA.

General distribution. END.

Local distribution. EP, RI (Wittmer 1979).

Collecting month and method. Abundant species that was collected by PT under canopies of $A$. ehrenbergiana, and by LT during IV-IX.

\section{Buprestidae}

Subfamily: Julodinae

Julodis euphratica Laporte \& Gory, 1835

World distribution. Asia: AF, EG (Sinai), IQ, IR, JO, OM, SA.

General distribution. SAR.

Local distribution. EP, QS, RI (Bílý 1982 1985). 
Collecting month and method. It is a rare and was collected by BV, HP and VC during I and IV-VI.

Subfamily: Polycestinae

Acmaeoderella arabica Cobos, 1963

World distribution. Asia: IL, IR, OM, SA.

General distribution. SAR.

Local distribution. RI (Cobos 1963).

Collecting month and method. Very rare species, which was collected by BV on branches of $Z$. nummularia during VI.

Xantheremia pantherina (Bílý, 1979)

World distribution. Asia: IL, IQ, SA. North Africa: EG.

General distribution. SAR.

Local distribution. EP, RI (Bílý 1982 1985).

Collecting month and method. A rare species. The specimens were collected by BV on branches of L. shawii, HP and by SW of R. stricta during V, VII and VIII.

Subfamily: Chrysochroinae

Sphenoptera gahani Kerremans, 1913

World distribution. Asia: Arabia (Kerremans 1913)

General distribution. END.

Local distribution. This species is described by Kerremans (1913) from Arabia, without any further information about the type locality.

Collecting month and method. Very rare species that was collected only by BV on branches of $A$. gerrardii during $\mathrm{X}$.

Sphenoptera magna Gory \& Laporte, 1839

World distribution. Asia: IL, IQ, IR, JO, SA, SY, TR.

General distribution. PAL_SAR.

Local distribution. EP, QS (Bílý 1980).

Collecting month and method. Very rare species that was collected by HP during $\mathrm{V}$. 


\section{Subfamily: Buprestinae}

Anthaxia kneuckeri Obenberger, 1920

World distribution. Asia: EG (Sinai), IL, JO, OM, SA.

General distribution. SAR.

Local distribution. AS, MK, RI (Bílý 1980), BA (El-Hawagry et al. 2013).

Collecting month and method. Common species. The adults were collected by $\mathrm{BV}$ and VC on branches of $A$. ehrenbergiana and $A$. gerrardii, and by HP, LT and PT during IV-XI.

Anthaxia marginifera metallenscens Bílý, 1999

World distribution. Asia: IL, SA.

General distribution. SAR.

Local distribution. RI (Bílý 1979).

Collecting month and method. Very rare species that was collected by BV on branches of $A$. ehrenbergiana during IV.

\section{Subfamily: Agrilinae}

Agrilus desertus (Klug, 1829)

World distribution. Africa: MR, SO, TD. Asia: IL, IR, JO, SA, YE. North Africa: DZ, EG, LY, MA, TN.

General distribution. AFR_SAR.

Local distribution. AS (Bílý 1982).

Collecting month and method. A rare species. The specimens were collected by BV on branches of A. ehrenbergiana, A. gerrardii and L. shawii, and HP during IV-V, VIII and X.

\section{Agrilus lituratus (Klug, 1829)}

World distribution. Africa: MR, SD, SN, TD (Bílý 1982). Asia: IL, IR, JO, SA, SY, YE. North Africa: DZ, EG, LY, MA, TN.

General distribution. AFR_SAR.

Local distribution. AS, BA, MK, RI (Bílý 1982).

Collecting month and method. Frequent species that was collected by BV, SW and $\mathrm{VC}$ on branches of $A$. ehrenbergiana, $A$. gerrardii and $C$. procera, and PT during IV-VII and IX. 
Trachys latifrons Kerremans, 1907

World distribution. Africa: ER, ET, SD. Asia: AE, SA, YE.

General distribution. AFR_SAR.

Local distribution. AS (Bílý 1979), RI (Al Dhafer et al. 2016).

Collecting month and method. Very rare species. It was collected by PT under the canopy of $Z$. nummularia during IV.

Heteroceridae

Subfamily: Heterocerinae

Augyles sericans (Kiesenwetter, 1843)

World distribution. Asia: IL, SY. Europe: AL, AT, BG, CH, CZ, DE, DK, ES, FR, GB, HR, HU, IT, NL, PL, RO, SE, SI, SK, UA. New to Arabian Peninsula.

General distribution. PAL_SAR.

Collecting month and method. Rare species that was collected by Lt during IV-V.

Augyles turanicus (Reitter, 1887)

World distribution. Asia: AE (Mascagni 2009), IL, IQ, IR, KZ, SY, TM, TR, UZ. Europe: GE. North Africa: DZ. New to KSA.

General distribution. PAL_SAR.

Collecting month and method. Very rare species, which was collected by LT in IV.

Elateridae

Subfamily: Agrypninae

Aeoloides grisescens (Germar, 1844)

World distribution. Africa: SD, TD. Asia: AE, AF, AZ, CN, CY, IQ, IR, KG, KZ, MN, OM, PK, QA, SA, SY, TJ, TM, TR, UZ, YE. Europe: AM, GE, GR, RU, UA. North Africa: EG, LY, MA.

General distribution.AFR_PAL_SAR_SJP.

Local distribution. EP, JZ, QS, RI (Platia and Schimmel 1997).

Collecting month and method. Common species. The adults were collected by PT under canopies of $A$. ehrenbergiana, L. shawii, R. stricta and $Z$. nummularia; and by $\mathrm{HP}$ and LT during I-VII and IX-X. 
Aeoloides holzschubi Platia \& Schimmel, 1997

World distribution. Asia: AE (Platia 2007), IR, OM, PA. New to KSA.

General distribution. SAR.

Collecting month and method. Frequent species that was collected by PT under canopies of A. ehrenbergiana, A. gerrardii, L. shawii and R. stricta; and by LT during I-V and XI.

Conoderus productus arabicus (Chassain, 1979)

World distribution. Asia: AE (Platia 2007), IR, OM, QA, SA, YE.

General distribution. SAR.

Local distribution. EP, MK, QS, RI (Chassain 1979 1983).

Collecting month and method. A frequent species. It was collected by LT through IV-VII.

Heteroderes gallagheri Platia \& Schimmel, 1997

World distribution. Asia: AE (Platia 2007), IR, OM, PK. New to KSA.

General distribution. SAR.

Collecting month and method. Frequent species. The adults were collected by LT through IV-VI and X.

Heteroderus ruteri Chassain, 1979

World distribution. Asia: OM, SA.

General distribution. SAR.

Local distribution. MD, MK, RI (Chassain 1979).

Collecting month and method. Very rare species that was collected by PT under canopies of $A$. gerrardii and $C$. procera during I-II.

Lacon modestus (Boisduval, 1835)

World distribution. Africa: SN. Asia: AE (Platia 2007), ID, IL, IQ, IR, JP, LA, OM, PK, QA, SA, TW, VN, YE (Socotra). Australia: AU, FJ, MP, NC. North America: GT, US. South America: GF.

General distribution. COS.

Local distribution. EP, MK, RI (Chassain 1983).

Collecting month and method. 28.XII.2011

Collecting method. Very rare species, which was collected by HP in XII. 
Lanelater buettikeri Chassain, 1983

World distribution. Asia: AE (Platia 2007), OM, SA, YE.

General distribution. SAR.

Local distribution. JZ, MK, NJ, RI (Chassain 1983, Platia and Schimmel 1997).

Collecting month and method. Frequent species. The beetles were collected by LT during VIII-X.

\section{Subfamily: Cardiophorinae}

Craspedostethus dilutus (Erichson, 1840)

World distribution. Africa: ER, ET, SO. Asia: AE, EG (Sinai), IR, OM, SA, SY, YE. North Africa: DZ, EG, MA. The distribution was updated from (Platia 2012).

General distribution. AFR_SAR.

Local distribution. BA, EP, MK (Platia and Schimmel 1997), RI (Al Dhafer et al. 2016).

Collecting month and method. Abundant species that was collected by PT under canopies of $Z$. nummularia and by LT during IV-IX.

Craspedostethus flavescens Chassain, 1979

World distribution. Asia: AE (Platia 2007), OM, SA, YE.

General distribution. SAR.

Local distribution. RI (Chassain 1979).

Collecting month and method. Frequent species, which was collected by LT in IV-V and VII-X.

Dicronychus brancuccii Platia \& Schimmel, 1997

World distribution. Asia: AE (Platia 2007), IQ, JO, KW, OM, QA, SA.

General distribution. SAR.

Local distribution. BA, EP, MK (Platia and Schimmel 1997).

Collecting month and method. Frequent species that was collected by LT through IV-VI.

Dicronychus latifae Al Dhafer \& Platia, 2013

World distribution. Asia: SA. 
General distribution. END.

Local distribution. RI (Al Dhafer and Platia 2013).

Collecting month and method. Abundant species that was collected by LT during IV.

Dicronychus talbouki Platia \& Schimmel, 1997

World distribution. Asia: SA, YE.

General distribution. SAR.

Local distribution. AS, BA (Platia and Schimmel 1997), RI (Al Dhafer et al. 2016).

Collecting month and method. Rare species, which was collected by PT under canopy of $A$. gerrardii, and by HP and LT during II-V.

Drasterius aegypticus Buysson, 1905

World distribution. Asia: SA, YE. North Africa: DZ, EG, LY, MA, TN.

General distribution. SAR.

Local distribution. JZ, RI (Platia and Schimmel 1997).

Collecting month and method. Rare species. It was collected by LT through III and V-VI.

Dermestidae

Subfamily: Dermestinae

Dermestes ater DeGeer, 1774

World distribution. Asia: AE, AF, AZ, CH, CN, CY, EG (Sinai), IL, IN, IQ, IR, JO, JP, KG, KP, KR, KZ, LB, MN, NP, OM, PK, RU, SA, SY, TJ, TM, TR, UZ, YE. Europe: AD, AL, AM, AT, BA, BE, BG, BY, CH, CZ, DE, DK, ES, FI, FR, GB, GE, GR, HR, HU, IE, IS, IT, LT, LU, LV, MK, MT, NL, NO, PL, PT, RO, RS, RU, SE, SI, SK, UA. North Africa: DZ, EG, ES (Canary Islands), LY, MA, PT (Madeira Archipelago), TN.

General distribution. COS (Háva 2013).

Local distribution. EP, RI (Mroczkowski 1979).

Collecting month and method. Very rare species. It was collected by LT during III.

Dermestes maculatus De Geer, 1774

World distribution. Asia: AE, AF, AZ, CN, CY, EG (Sinai), IL, IN, IQ, IR, JO, JP, KG, KP, KR, KZ, LB, MN, NP, OM, PK, RU, SA, SY, TJ, TM, TR, UZ, YE. Europe: AD, 
AL, AM, AT, BA, BE, BG, BY, CH, CZ, DE, DK, EE, ES, FI, FR, GB, GE, GR, HR, HU, IE, IS, IT, LT, LU, LV, MK, MT, NL, NO, PL, PT, RO, RS, RU, SE, SI, SK, UA. North Africa: DZ, EG, ES (Canary Islands), LY, MA, PT (Madeira Archipelago), TN.

General distribution. COS (Háva 2003).

Local distribution. MK (Mroczkowski 1979), RI (Al Dhafer et al. 2016).

Collecting month and method. Very rare species. The adult was collected by LT and PT during III and V.

\section{Subfamily: Thorictinae}

Thorictodes heydeni Reitter, 1875

World distribution. Africa: SD. Asia: CN, IL, IN, JP, PK, TR. Australia: AU. Europe: ES, FR, GB, IT, RU. North Africa: DZ, EG, MA. North America: CA, MX, US. New to Arabian Peninsula.

General distribution. SCO.

Collecting month and method. Very rare species. The beetles were collected by PT under the canopies of $A$. ehrenbergiana, A. gerrardii, C. procera and $L$. shawii during IV.

\section{Thorictus castaneus Germar, 1834}

World distribution. Asia: SY. North Africa: DZ, EG, LY, MA. New to Arabian Peninsula.

General distribution. SAR.

Collecting month and method. Very rare species. It was collected by PT under the canopies of $A$. gerrardii, C. procera and L. shawii during IV-VI.

\section{Thorictus foreli Wasmann, 1894}

World distribution. North Africa: DZ, MA, TN. New to Arabian Peninsula.

General distribution. SAR.

Collecting month and method. Very rare. The species was collected by PT under the canopy of $A$. gerrardii during XII.

Subfamily: Attageninae

Attagenus fasciolatus (Solsky, 1876) 34

World distribution. Asia: KZ, MN, SA, TJ, TM, UZ. 
General distribution. PAL_SAR.

Local distribution. EP (Mroczkowski 1979), RI (Al Dhafer et al. 2016).

Collecting month and method. A frequent species. The adults were collected by $\mathrm{BV}, \mathrm{SW}, \mathrm{VC}$ and PT on branches/under the canopies of $A$. gerrardii, C. procera, $R$. stricta and $Z$. nummularia; and by MT through V-VI and VIII-XI.

\section{Attagenus lobatus Rosenhauer, 18561}

World distribution. Asia: AE, AF, CN, IN, IQ, IR, KG, KZ, MN, PK, SA, TJ, TM, TR, UZ. Europe: BG, CZ, ES, FR, GR, IT, RO, RU. North Africa: DZ, EG, MA, TN. The distribution is updated from Háva (2013).

General distribution. PAL_ORR_SAR_SJP.

Local distribution. EP, MK (Mroczkowski 1979), RI (Al Dhafer et al. 2016).

Collecting month and method. Very rare species. It is collected by PT under canopy of $C$. procera during $\mathrm{V}$.

\section{Attagenus posticalis Fairmaire, 1879}

World distribution. Africa: MR, NE, SD, SN. Asia: AE, IL, OM, QA, SA, SY, YE. Europe: ES. North Africa: DZ, EG, MA, TN. The distribution is updated from Háva (2013).

General distribution. AFR_SAR.

Local distribution. EP (Háva 2011); RI (Alqarni et al. 2015; Al Dhafer et al. 2016).

Collecting month and method. Frequent species. The adults were collected by $\mathrm{BV}, \mathrm{SW}, \mathrm{VC}$ and PT on branches/under canopies of $A$. ehrenbergiana, $A$. gerrardii, $C$. procera, $R$. stricta and $Z$. nummularia through IV-X.

Attagenus reitteri (Mroczkowski, 1968)

World distribution. Europe: ES, PT. North Africa: DZ, MA, TN. New to Arabian Peninsula.

General distribution. SAR.

Collecting month and method. Very rare species that was collected by SW on branches of $R$. stricta during II.

Attagenus scalaris (Pic, 1893)

World distribution. North Africa: EG, LY. New to Arabian Peninsula.

General distribution. SAR.

Collecting month and method. Very rare species. It was collected by SW during VI. 


\section{Subfamily: Megatominae}

Anthrenus buettikeri Mruczkowski, 1980

World distribution. Asia: SA.

General distribution. END.

Local distribution. RI (Mroczkowski 1980).

Collecting month and method. Very rare species. The specimens were collected by BV on branches and PT canopies of $A$. gerrardii, $R$. stricta and $Z$. nummularia during IV, VI-VII and X.

\section{Anthrenus flavipes LeConte, 1854}

World distribution. Asia: AE (Háva 2013), AF, CN, IL, IR, JP, OM, RU, SA, TJ. Europe: CZ, DE, DK, ES, FI, FR, GB, IT, NL. North Africa: EG, MA, TN.

General distribution. COS (Háva 2013).

Local distribution. MK, RI (Mroczkowski 1979).

Collecting month and method. Very rare species that was collected by BV on branches of $Z$. nummularia in IX.

\section{Anthrenus malkini Mroczkowski, 1980}

World distribution. Asia: AE, OM, QA, SA, YE (Háva 2013).

General distribution. SAR.

Local distribution. AS (Mroczkowski 1980).

Collecting month and method. Very rare species. The beetles were collected by $\mathrm{BV}$ and SW on branches of $Z$. nummularia in IV and IX.

\section{Anthrenus verbasci (Linnaeus, 1767)}

World distribution. Asia: AE, AF, AZ, CN, CY, EG (Sinai) IL, IN, IQ, IR, JO, JP, KG, KP, KR, KZ, LB, MN, NP, OM, PK, RU, SA, SY, TJ, TM, TR, UZ, YE. Europe: $\mathrm{AD}, \mathrm{AL}, \mathrm{AM}, \mathrm{AT}, \mathrm{BA}, \mathrm{BE}, \mathrm{BG}, \mathrm{BY}, \mathrm{CH}, \mathrm{CZ}, \mathrm{DE}, \mathrm{DK}, \mathrm{EE}, \mathrm{ES}, \mathrm{FI}, \mathrm{FR}, \mathrm{GB}$, GE, GR, HR, HU, IE, IS, IT, LT, LU, LV, MK, MT, NL, NO, PL, PT, RO, RS, RU, SE, SI, SK, UA. North Africa: DZ, EG, ES (Canary Islands), LY, MA, PT (Madeira Archipelago), TN. COS.

General distribution. PAL_ORR_SAR_SJP.

Local distribution. RI (Alqarni et al. 2015; Al Dhafer et al. 2016).

Collecting month and method. Common species that was collected by BV, VC, $\mathrm{SW}$ and $\mathrm{PT}$ on branches/under canopies of $A$. ehrenbergiana, A. gerrardii, C. procera, $R$. stricta and $Z$. nummularia; and by LT through IV-X. 


\section{Phradonoma nobile (Reitter, 1881)}

World distribution. Africa: ER, NA, SD, TJ, ZA, ZW. Asia: AE, AF, CY, IL, IN, IQ, IR, JO, PK, QA, SA, SY, TJ, TM, UZ. Europe: ES, GB, GR, PT. North Africa: DZ, EG, LY, MA, TN. The distribution is updated from Háva (2013).

General distribution. AFR_ORR_PAL_SAR.

Local distribution. AS, RI (Mroczkowski 1979).

Collecting month and method. A frequent species. The specimens were collected by BV, VC, SW and PT on branches/under canopies of $A$. ehrenbergiana, A. gerrardii, C. procera, $R$. stricta and Z. nummularia; and by LT through IV-X.

Bostrichidae

Subfamily: Bostrichinae

Enneadesmus forficula (Fairmaire, 1883)

World distribution. Africa: ER, ET, SO. Asia: AE (Geistharde 2010), IL, IR, JO, OM, PK, SA, YE. North Africa: DZ, EG, LY, MA, TN.

General distribution. AFR_SAR.

Local distribution. MK, RI (Damoiseau 1979).

Collecting month and method. Common species that was collected by BV and LT during all months except II and VII.

Sinoxylon senegalense Karsch, 1881

World distribution. Africa: SN. Asia: AE (Geistharde 2010), SA, YE. North Africa: DZ, EG, LY, MA.

General distribution. AFR_SAR.

Local distribution. RI (Damoiseau 1979).

Collecting month and method. Frequent species that was collected by BV and LT during all months except II, III and VIII.

Subfamily: Lyctinae

Acantholyctus cornifrons (Lesne, 1898)

World distribution. Africa: DJ, ER, MZ, NA, SN, SO. Asia: AE (Geistharde 2010). North Africa: DZ, EG, MA, TN. New to KSA.

General distribution. AFR_SAR.

Collecting month and method. Rare species and its adults were collected by BV and LT during V, IX and X. 
Ptinidae

Subfamily: Xyletininae

Lasioderma baudii Schilsky, 1899

World distribution. Asia: CY, IL, LB, SY. Europe: ES, FR, GR, HR, IT, PT. North Africa: DZ, EG, ES (Canary Islands), LY, TN. New to Arabian Peninsula.

General distribution. PAL_SAR.

Collecting month and method. Very rare species, which was collected by LT during IX-X.

Lasioderma redtenbacheri (Bach, 1852)

World distribution. Asia: AZ, CY, EG (Sinai), IL, IQ, KZ, MN, SY, TM, TR, UZ. Europe: AM, AT, BE, BG, CH, CZ, DE, ES, FR, GE, GR, HR, HU, IT, MK, NL, PL, PT, RO, RU, SK, UA. North Africa: EG, LY, TN. New to Arabian Peninsula.

General distribution. PAL_SAR.

Collecting month and method. A rare species. The adult beetles were collected by LT during IV-V and X.

Subfamily: Dorcatominae

Stagetus montanus Toskina, 1998

World distribution. Asia: OM, SA.

General distribution. SAR.

Local distribution. AS (Toskina 1998).

Collecting month and method. Very rare species. It was collected by LT in V.

Thanerocleridae

Subfamily: Thaneroclerinae

Thaneroclerus buquet (Lefebvre, 1835)

World distribution. Asia: CN, IN, JP, RU, SA, TW. Europe: BE, DE, HU, NL, PL. North Africa: EG.

General distribution. ORR_PAL_SAR_SJP.

Local distribution. BA (El-Hawagry et al. 2013), RI (Al Dhafer et al. 2016).

Collecting month and method. A rare species. It was collected by BV on branches and PT under canopies of $A$. ehrenbergiana, A. gerrardii and C. procera during V-VII. 


\section{Cleridae}

Subfamily: Tillinae

Eucymatodera senegalensis (Castelanu, 1832)

World distribution. Africa: SN. Asia: AE, IR, OM, SA, YE. North Africa: DZ, EG, LY, TN. The distribution is updated from Gerstmeier (2010)

General distribution. AFR_SAR.

Local distribution. BA, EP, JZ, RI (Menier 1986).

Collecting month and method. Frequent species that was collected by LT during $\mathrm{V}$ and IX-X.

Tillodenops plagiatus (Fairmaire, 1892)

World distribution. Africa: KE, MR, SD, SN, SO, TZ. Asia: AE, IR, OM, SA, YE. The distribution is updated from Gerstmeier (2010)

General distribution. AFR_SAR.

Local distribution. AS, BA, JZ, MD, MK (Menier 1986).

Collecting month and method. Very rare species, which was collected by LT during IV and X.

Wittmeridecus mediozonatus (Fairmaire, 1892)

World distribution. Africa: DJ. Asia: AE, IL, OM, SA, SY, YE. Europe: ES, IT. North Africa: DZ, EG, LY, MA. The distribution is updated from Gerstmeier (2010)

General distribution. AFR_PAL_SAR.

Local distribution. AS, MD, MK, RI (Menier 1986).

Collecting month and method. A frequent species. The adults were collected by VC on branches of $A$. ehrenbergiana and by LT through IV-X.

\section{Subfamily: Korynetinae}

Necrobia rufipes (De Geer, 1775)

World distribution. Asia: AE, AZ, CN, IN, IR, JP, MN, OM, RU, SA, TJ, TR. Europe: $\mathrm{AM}, \mathrm{AT}, \mathrm{BE}, \mathrm{BY}, \mathrm{CH}, \mathrm{CZ}, \mathrm{DE}, \mathrm{DK}, \mathrm{EE}, \mathrm{ES}, \mathrm{FI}, \mathrm{FR}, \mathrm{GB}, \mathrm{GR}, \mathrm{HR}, \mathrm{HU}, \mathrm{IE}$, IT, LI, LT, LV, NL, PT, RO, RU, SE, SI, SK. North Africa: DZ, EG, ES (Canary Islands), LY, MA, TN. 
General distribution. COS (Gerstmeier 2010)

Local distribution. BA (El-Hawagry et al. 2013), EP, MK, RI (Menier 1986).

Collecting month and method. Frequent species, which was collected by VC on branches of L. shawii and by LT during IV-VIII and X.

Melyridae

Subfamily: Dasytinae

Danacea sp.

Collecting month and method. Frequent species. The specimens were collected by $\mathrm{BV}, \mathrm{SW}$ and PT on branches/under canopies of $A$. ehrenbergiana, A. gerrardii, C. procera, L. shawii, R. stricta and Z. nummularia; and by HP and LT during II-V and XII.

\section{Subfamily: Malachinae}

Colotes javeti Du Val, 1852

World distribution. Europe: ES, FR, IT, PT. North Africa: DZ, EG, MA, TN. New to Arabian Peninsula.

General distribution. PAL_SAR.

Collecting month and method. A frequent species. The beetles were collected by $\mathrm{BV}, \mathrm{SW}, \mathrm{VC}$ and PT on branches/under canopies of $A$. ehrenbergiana, A. gerrardii, $C$. procera, L. shawii, R. stricta and Z. nummularia; and by HP during II-VI and IX.

\section{Malachius sp. 1}

Collecting month and method. A common species. The adults were collected by BV, SW, VC and PT on branches/under canopies of A. ehrenbergiana, A. gerrardii, C. procera, L. shawii, R. stricta and Z. nummularia; and by HP and LT through V-IX.

\section{Malachius sp.2}

Collecting month and method. A rare species. It was collected by BV on branches of $A$. gerrardii and $Z$. nummularia, by $\mathrm{PT}$ under canopies of $A$. ehrenbergiana and $C$. procera; and by HP in III-IV and IX. 


\section{Cryptophagidae}

Subfamily: Cryptophaginae

Cryptophagus acutangulus Gyllenhal, 1827

World distribution. Africa: sub-saharan Africa. Asia: AF, AZ, CN, EG (Sinai), IR, JP, KG, KP, KZ, PK, RU, SA, TJ, TM, UZ. Europe: AT, BA, BE, BY, CH, CZ, DE, DK, EE, FI, FR, GB, GE, GR, HU, IE, IS, IT, LT, LV, NL, NO, PL, RO, RS, RU, SE, SI, SK, UA. North Africa: EG, MA. North America: CA, MX, US.

General distribution. COS (Otero 2013).

Local distribution. EP (Johnson 1989), RI (Al Dhafer et al. 2016).

Collecting month and method. Frequent species. The adults were collected by $\mathrm{BV}$ on branches and PT under canopies of A. ehrenbergiana, A. gerrardii, C. procera, L. shawii, R. stricta and Z. nummularia; and by LT during I-III, V, VIII and XI-XII.

\section{Subfamily: Atomariinae}

Atomaria fuscata (Schönherr, 1808)

World distribution. Asia: AZ, CN, IL, JP, RU. Europe: AM, AT, BA, BE, BY, CH, CZ, DE, DK, EE, ES, FI, FR, GB, GE, GR, HR, HU, IE, IT, LI, LT, LV, NL, NO, PL, RO, RU, SE, SI, SK, UA. North America: CA. New to Arabian Peninsula.

General distribution. NAR_PAL_SAR_SJP.

Collecting month and method. Very rare species that was collected by LT in X.

Phalacridae

Subfamily: Phalacrinae

Olibrosoma testacea Tournier, 1889

World distribution. Asia: AE (Švec 2010b), JO, SA. Europe: ES. North Africa: DZ, EG, MA, TN.

General distribution. SAR.

Local distribution. RI (Al Dhafer et al. 2016).

Collecting month and method. Afrequent species. The adults were collected by PT under canoppy of $A$. ehrenbergiana, and by LT during IV-X. 


\section{Laemophloeidae}

Subfamily: Laemophloeinae

Placonotus testaceus (Fabricus, 1787)

World distribution. Asia: AZ, BT, CN, IN, JP, KG, KZ, RU, TW, UZ. Australia: AU. Europe: AM, BE, CH, CZ, DE, DK, ES, FR, GE, IT, PL, PT, SK. North Africa: DZ, TN. New to Arabian Peninsula.

General distribution. SCO.

Collecting month and method. Very rare species that was collected by LT during VIII and XI.

\section{Nitidulidae}

Subfamily: Carpophilinae

Carpophilus hemipterus (Linnaeus, 1758)

World distribution. Africa: MR, ZA. Asia: AE, AZ, CN, IL, IN, IQ, IR, JO, JP, LB, SA, TM, TR, TW. Europe: AL, AT, BA, BE, BY, CH, CZ, DE, DK, ES, FI, FR, GB, GR, HR, HU, IE, IS, IT, LV, MD, MT, NL, PL, PT, SE, SK. North Africa: DZ, EG, ES (Canary Islands), LY, PT (Madeira Archipelago), TN. North America: GT, MX, NI, PA, US.

General distribution. COS (Jelinek 1979).

Local distribution. EP, MK, RI (Beccari 1971, Jelinek 1979 1988).

Collecting month and method. Rare species. The adult beetles were collected by PT under canoppy of $R$. stricta, and by HP and LT during IV-V and XI.

\section{Subfamily: Nitidulinae}

Nitidula eremita Audisio, 1990

World distribution. Asia: AE, IL, IQ, IR, SA. North Africa: DZ, EG, LY, TN.

General distribution. SAR.

Local distribution. EP, RI, (Jelinek 1979 1988).

Collecting month and method. Frequent species that was collected by PT under canoppy of L. shawii during I, and by LT during III and X-XII. 


\section{Subfamily: Cybocephalinae}

Cybocephalus rufifrons flaviceps Reitter, 1874

World distribution. Asia: IQ, IR, SA, TR. North Africa: DZ, EG, MA, TN.

General distribution. SAR.

Local distribution. MK (Endrödy-Younga 1979), RI (Beccari 1971).

Collecting month and method. A common species. The specimens were collected by BV, SW and VC on branches of A. ehrenbergiana, A. gerrardii, C. procera, L. shawii, R. stricta and Z. nummularia; and by MT through II, V-IX and XII.

Coccinellidae

Subfamily: Coccinellinae

Bulaea lividula bocandei Mulsant, 1850

World distribution. Africa: ER. Asia: AE, IL, IQ, IR, JO, PK, SA, SY, YE. North Africa: DZ, EG, MA.

General distribution. AFR_SAR.

Local distribution. EP (Fürsch 1979).

Collecting month and method. Very rare species that was collected by BV on branches of $Z$. nummularia in VIII.

Coccinella septempunctata Linnaeus, 1758

World distribution. Africa: ZA. Asia: AF, AZ, BT, CN, CY, EG (Sinai), IL, IN, IQ, IR, JO, JP, KG, KP, KR, KW, KZ, LB, MN, NP, PK, RU, SA, SY, TJ, TM, TR, TW, UZ. Europe: AD, AL, AM, AT, BA, BE, BG, BY, CH, CZ, DE, DK, EE, ES, FI, FR, GB, GE, GR, HR, HU, IE, IT, LI, LT, LU, LV, MD, MK, NL, NO, PL, PT, RO, RS, RU, SE, SI, SK, UA. North Africa: PT (Madeira Archipelago). North America: CA, US.

General distribution. SCO.

Local distribution. RI (Fürsch 1979).

Collecting month and method. Very rare species, which was collected by SW during IV.

Coccinella undecimpunctata menetriesi Mulsant, 1850

World distribution. Asia: AE, AF, CN, EG (Sinai), IL, IN, IQ, IR, JO, KG, KW, KZ, MN, PK, RU, SA, SY, TR. Europe: GR, IT, PT, RU. North Africa: DZ, EG, LY, TN. 
General distribution. PAL_ORR_SAR_SJP.

Local distribution. RI (Fürsch 1979).

Collecting month and method. A frequent species. The adult beetles were collected by BV, SW, VC and PT on branches/under canopies of $A$. ehrenbergiana, $A$. gerrardii, C. procera, L. shawii, R. stricta and Z. nummularia during I-IV and XI.

\section{Diomus rubidus (Motschulsky, 1837)}

World distribution. Asia: IL, IQ, IR, LB, SA, SY, YE. Europe: AM, FR, GR, HR, IT. North Africa: DZ, EG, LY, MA, TN.

General distribution. PAL_SAR.

Local distribution. RI (Fürsch 1979).

Collecting month and method. Frequent species. The specimens were collected by $\mathrm{BV}$ and SW on branches and PT under canopies of $A$. ehrenbergiana, A. gerrardii, C. procera, L. shawii, and R. stricta through I-VII.

\section{Hippodamia variegata (Goeze, 1777)}

World distribution. Africa: SZ, ZA. Asia: AE, AF, AZ, BT, CN, EG (Sinai), IL, IN, IQ, IR, JO, KG, KP, KR, KZ, LB, MN, NP, PK, RU, SA, SY, TJ, TM, TR, UZ, YE. Europe: AD, AL, AM, AT, BA, BE, BG, BY, CH, CZ, DE, DK, EE, ES, FI, FR, GB, GE, GR, HR, HU, IT, LI, LT, LU, LV, MD, MK, NL, PL, PT, RO, RS, RU, SE, SI, SK, UA. North Africa: DZ, EG, ES (Canary Islands), LY, MA, PT (Madeira Archipelago), TN. North America: US.

General distribution. COS.

Local distribution. BA (El-Hawagry et al. 2013), JZ (Beccari 1971), RI (Talhouk 1982; Al Dhafer et al. 2016).

Collecting month and method. Frequent species. The specimens were collected by BV, SW, VC and PT on branches/ under canopies of $A$. gerrardii, C. procera, $L$. shawii, R. stricta and Z. nummularia; and by LT and MT in I and III-IV.

\section{Hyperaspis vinciguerrae Capra, 1929}

World distribution. Africa: GM, SN. Asia: AE (Raimundo et al. 2007), SA, YE. North Africa: LY.

General distribution. AFR_SAR.

Local distribution. RI (Talhouk 1982)

Collecting month and method. Rare species that was collected by BV, SW and $\mathrm{VC}$ on branches of $C$. procera, $L$. shawii, $R$. stricta and $Z$. nummularia; and MT during V-VIII. 
Nephus arcuatus Kapur, 1959

World distribution. Africa: TG. Asia: AE (Raimundo et al. 2007), IR, SA, YE.

General distribution. AFR_SAR.

Local distribution. AS (Fürsch 1979).

Collecting month and method. Very rare species, which was collected by VC on branches of $Z$. nummularia in VII.

Nephus levaillanti (Mulsant, 1850)

World distribution. Africa: ZA. Asia: AF, CN, IL, IN, IR, JO, JP, LB, PK, RU, SA, TW, YE. Europe: GR, IT. North Africa: EG.

General distribution. AFR_ORR_PAL_SAR_SJP.

Local distribution. RI (Al Dhafer et al. 2016).

Collecting month and method. Very rare species. The specimens were collected by $\mathrm{BV}$ on branches of $A$. gerrardii and $Z$. nummularia; and by PT under canopies of $A$. ehrenbergiana and $A$. gerrardii during IV and VII.

Nephus wittmeri Fürsch, 1979

World distribution. Asia: SA, YE.

General distribution. SAR.

Local distribution. RI (Fürsch 1979).

Collecting month and method. Rare species. The adults were collected by BV on branches of $A$. ehrenbergiana $A$. gerrardii and $Z$. nummularia; by PT under canopy of A. ehrenbergiana; and by VC on branches of $R$. stricta during II-V and XII.

\section{Parexochomus pubescens (Küster, 1848)}

World distribution. Africa: Africa. Asia: AE (Raimundo et al. 2007), AF, IL, IN, IQ, IR, SA, SY, YE. Europe: ES, FR, GR, IT. North Africa: DZ, EG, LY, MA, TN.

General distribution. AFR_ORR_PAL_SAR

Local distribution. AS, RI (Fürsch 1979).

Collecting month and method. Common beetles that were collected by BV and VC on branches of $A$. ehrenbergiana A. gerrardii, C. procera and L. shawii throughout the year except in VI and VIII. 
World distribution. Asia: SA. North Africa: EG.

General distribution. SAR.

Local distribution. RI (Fürsch 1989).

Collecting month and method. Very rare species that was collected by SW on branches of $R$. stricta during XII.

\section{Scymnus nubilus Mulsant, 1850}

World distribution. Africa: KE, SZ, UG. Asia: AE (Raimundo et al. 2007), AF, BD, IL, IN, IQ, IR, JO, JP, KW, LB, NP, OM, PK, SA, SY, TR, TW, YE. Australia: AU. Europe: ES, GR, IT, PT. North Africa: EG, ES (Canary Islands), PT (Madeira Archipelago).

General distribution. SCO.

Local distribution. AS (Fürsch 1979; Raimundo et al 2006); RI (Al Dhafer et al. 2016).

Collecting month and method. A rare species, which was collected by PT under canopy of $L$. shawii, and by LT and MT during V and VII-VIII.

Scymnus subvillosus (Goeze, 1777)

World distribution. Africa: ZA. Asia: AE, AF, AZ, CY, EG (Sinai), IL, IQ, IR, JO, KG, KW, KZ, LB, PK, QA, SA, SY, TJ, TR, UZ, YE. Europe: AD, AL, AM, AT, BA, BG, CH, CZ, DE, ES, FR, GE, GR, HR, HU, IT, MK, PT, RO, RS, RU, SI, SK, UA. North Africa: DZ, EG, ES (Canary Islands), LY, MA, PT (Madeira Archipelago), TN.

General distribution. AFR_PAL_SAR.

Local distribution. AS, RI (Fürsch 1979).

Collecting month and method. Common species. The adults were collected by $\mathrm{BV}, \mathrm{SW}, \mathrm{VC}$ and PT on branches/under canopies of $A$. ehrenbergiana $A$. gerrardii, $C$. procera, L. shawii, R. stricta and $Z$. nummularia throughout the year except in X.

\section{Scymnus syriacus (Marseul, 1868)}

World distribution. Asia: CY, EG (Sinai), IL, IQ, IR, JO, LB, SA, SY. North Africa: EG. General distribution. SAR.

Local distribution. BA (El-Hawagry et al. 2013), EP (Fürsch 1989).

Collecting month and method. A common species that was collected by BV, SW and VC on branches of A. ehrenbergiana A. gerrardii, C. procera, L. shawii, R. stricta and $Z$. nummularia; and by HP during II-VII and X-XII. 
Scymnus yemenensis (Kapur, 1959)

World distribution. Asia: AE (Raimundo et al. 2007), OM, SA, YE.

General distribution. SAR.

Local distribution. AS, RI (Fürsch 1979).

Collecting month and method. A rare species that was collected by BV on branches of $A$. ehrenbergiana, by SW and VC on branches of $C$. procera, and by LT during IV and X.

Mycetophagidae

Subfamily: Mycetophaginae

Typhaea stercorea (Linnaeus, 1758)

World distribution. Africa: GM, MR, ZA. Asia: AE, AF, AZ, BT, CN, CY, EG (Sinai), IL, IQ, IR, JO, JP, KG, KR, KZ, MN, NP, PK, RU, SA, SY, TJ, TM, TR, UZ, YE. Europe: AD, AL, AM, AT, BA, BE, BG, BY, CH, CZ, DE, DK, EE, ES, FI, FO, FR, GB, GE, GR, HR, HU, IE, IS, IT, LI, LT, LU, LV, MD, MK, MT, NL, NO, PL, PT, RO, RS, RU, SE, SI, SK, UA. North Africa: DZ, EG, ES (Canary Islands), LY, MA, PT (Madeira Archipelago), TN. South America: CL.

General distribution. COS.

Local distribution. BA (El-Hawagry et al. 2013).

Collecting month and method. Very rare species. The adults were collected by LT during $\mathrm{V}$.

Tenebrionidae

Subfamily: Lagriinae

Centorus csikii bagdadensis (Reitter, 1920)

World distribution. Asia: CY, IL, IQ, JO, SA, YE.

General distribution. SAR.

Local distribution. EP, RI (Kaszab 1979).

Collecting month and method. Common beetles that were collected by PT under the canopies $A$. ehrenbergiana, A. gerrardii and $Z$. nummularia; and by LT throughout the year except in XI. 


\section{Subfamily: Pimeliinae}

Adelostoma subtile Reitter, 1900

World distribution. Asia: IL, IR, JO, SA, SY, TR.

General distribution. PAL_SAR.

Local distribution. MD, NJ, RI (Kaszab 1981 1982).

Collecting month and method. A frequent species. The adults were collected by PT under the canopies A. ehrenbergiana, A. gerrardii, R. stricta and Z. nummularia; and by HP through II, IV-V, and VII-X.

\section{Adesmia cancellata (Klug, 1830)}

World distribution. Asia: AE, BH, EG (Sinai), IL, IR, IQ, JO, KW, OM, PK, SA, SY, YE. The distribution is updated from Schawaller (2010).

General distribution. SAR.

Local distribution. AS, BA, EP, JZ, MD, MK, NJ, RI (Kaszab 19791981 1982; El-Hawagry et al. 2013).

Collecting month and method. Very rare species. It was collected by PT under canopy of $A$. ehrenbergiana and $L$. shawii in III and V.

Akis spinosa (Linnaeus, 1764)

World distribution. North Africa: EG. New to Arabian Peninsula,

General distribution. SAR.

Collecting month and method. Very rare species that was collected by PT under canopy of $L$. shawii during VII.

Akis subtricostata Redtenbacher, 1850

World distribution. Asia: AE (Schawaller 2010), IQ, IR, SY. New to KSA.

General distribution. SAR.

Collecting month and method. Very rare species, which was collected by LT in IX.

Ammogiton sonyae Kaszab, 1979

World distribution. Asia: SA.

General distribution. END.

Local distribution. EP, RI (Kaszab 19791981 1982).

Collecting month and method. Very rare species that was collected by HP during II. 
Apentanodes arabicus (Kirchsberg, 1877)

World distribution. Asia: AE, OM, SA.

General distribution. SAR.

Local distribution. AS, EP, HA, MD, MK, QS, RI, (Kaszab 19791981 1982).

Collecting month and method. Common beetles that were collected by PT under canopies of $A$. ehrenbergiana, A. gerrardii, C. procera, L. shawii, R. stricta and $Z$. nummularia; and by HP and LT through I-VI.

Boromorphus saudicus Schawaller, Al Dhafer \& Fadl, 2013

World distribution. Asia: SA (Schawaller et al. 2013).

General distribution. END.

Local distribution. RI (Schawaller et al. 2013).

Collecting month and method. A rare beetle. The adults were collected by PT under canopies of A. ehrenbergiana, A. gerrardii, C. procera, L. shawii and Z. nummularia; and by HP during II-IV.

Cyphostethe ferruginea (Marseul, 1867)

World distribution. Asia: AE, IL, SA. North Africa: DZ, LY, TN.

General distribution. SAR.

Local distribution. AS, RI (Kaszab 1981).

Collecting month and method. Very rare species that was collected by PT under canopy of C. procera in X.

Cyphostethe wittmeri Kaszab, 1979

World distribution. Asia: AE, SA.

General distribution. SAR.

Local distribution. EP, HA, MK, RI (Kaszab 19791981 1982).

Collecting month and method. A rare species. The specimens were collected by LT through V-IX.

Erodius glabratus Solier, 1834

World distribution. Asia: EG (Sinai), SA. North Africa: EG.

General distribution. SAR.

Local distribution. AS, EP, HA, JF, JZ, MD, MK, QS, TB, (Kaszab 19791981 1982).

Collecting month and method. Very rare species that was collected by LT in IV. 
Erodius octocostatus Peyerimhoff, 1907

World distribution. Asia: EG (Sinai), IQ, JO, SA. North Africa: EG.

General distribution. SAR.

Local distribution. ES, NJ (Kaszab 1981).

Collecting month and method. Very rare species. The beetles were collected by HP during II and XII.

Erodius servillei Solier, 1834

World distribution. Asia: AF, IQ, IR, SA, SY.

General distribution. SAR.

Local distribution. MK, QS, RI (Kaszab 1979 1981)

Collecting month and method. Very rare species that was collected by PT under canopy of $R$. stricta through III.

Mesostena angustata (Fabricius, 1775)

World distribution. Africa: ER, NG, SD. Asia: EG (Sinai), IL, IQ, IR, JO, LB, SA (Al Dhafer et al. 2016), SY. North Africa: DZ, EG, LY, TN.

General distribution. AFR_SAR.

Local distribution. RI (Al Dhafer et al. 2016).

Collecting month and method. Very rare species. The specimens were collected by PT under canopy of $A$. gerrardii through V; and by HP in V and XII.

Mesostena puncticollis Solier, 1835

World distribution. Africa: SD, SO. Asia: AE, EG (Sinai), IL, IQ, IR, JO, SA, SY, TM, YE. Europe: AM. North Africa: EG.

General distribution. AFR_PAL_SAR.

Local distribution. AS, EP, HA, MD, MK, NJ, QS, RI, TB (Kaszab 19791981 1982).

Collecting month and method. An abundant species. The adults of this beetle were collected by HP, LT and PT all over the year except in XI.

Oxycara saudarabica Kaszab, 1979

World distribution. Asia: AE, SA.

General distribution. SAR. 
Local distribution. EP, RI (Kaszab 19791981 1982).

Collecting month and method. Common species that was collected by HP, LT and PT throughout the year.

Paraplatyope arabica arabica (Blair, 1931)

World distribution. Asia: AE, KW, SA.

General distribution. SAR.

Local distribution. EP, MK, RI (Kaszab 1979 1982).

Collecting month and method. Very rare species that was collected by LT during III.

Pimelia arabica (Klug, 1830)

World distribution. Asia: AE, BH, IL, IQ, JO, KW, OM, PK, SA, SY, YE. North Africa: EG.

General distribution. SAR.

Local distribution. AS, BA, EP, HA, MD, MK, RI (Kaszab 1979 1982)

Collecting month and method. A rare species. The beetles were collected by HP and PT in X-XII.

Pimelia longula Kwieton, 1981

World distribution. Asia: $\mathrm{BH}, \mathrm{SA}$.

General distribution. SAR.

Local distribution. EP, MD, RI, TB (Kaszab 1979 1982).

Collecting month and method. Very rare species that was collected by HP during I.

Prionotheca coronata ovalis Ancey, 1881

World distribution. Asia: AE, BH, IQ, IR, SA, YE.

General distribution. SAR.

Local distribution. AS, EP, HA, MD, MK, QS, RI (Kaszab 1979 1982).

Collecting month and method. A rare species. This beetle was collected by HP, LT and PT during II, IV, VI and X.

Thriptera kraatzi Haag-Rutenberg, 1876

World distribution. Asia: AE, EG (Sinai), IN, IR, JO, OM, PK, SA, YE. North Africa: AG. 
General distribution. ORR_SAR.

Local distribution. AS, BA, MK, RI (Kaszab 1979 1982; El-Hawagry et al. 2013).

Collecting month and method. A frequent species. The specimens were collected by HP and PT during III-VI and VIII.

\section{Trachyderma philistina Reiche \& Saulcy, 1857}

World distribution. Asia: AE, BH, CY, EG (Sinai), IL, IQ, IR, JO, OM, SA, SY, TR, YE. Europe: GR. North Africa: EG. According to the Palaearctic catalogue Trachyderma philistina occurs east of the Arabian Peninsula also in Iran and in the ORR region (Löbl et al. 2008). However, the known distribution of species indicates its absence from Afghanistan, Pakistan, and India. The only record available from western India apparently is by Kaszab (1982). This record is a misidentification and Kaszab (1982) did not specifically mention this species from Afghanistan (W. Schawaller, personal communication, February 29 2016).

General distribution. PAL_SAR.

Local distribution. EP, HA, MK, NJ, QS, RI, TB (Kaszab 1979 1982)

Collecting month and method. Rare species that was collected by HP and PT through III-VI, X and XII.

\section{Trichosphaena arabica Kaszab, 1961}

World distribution. Asia: AE, OM, SA, YE.

General distribution. SAR.

Local distribution. HA, JZ, MK, NJ, QS, RI (Kaszab 19791981 1982).

Collecting month and method. A frequent species. The adults of this species were collected by BV on branches of $A$. ehrenbergiana and $Z$. nummularia, and by HP during IV and VII-IX.

\section{Zophosis punctata Brullé, 1832}

World distribution. Asia: AF, AZ, CN, CY, EG (Sinai), IL, IQ, IR, JO, KZ, LB, PK, SA, SY, TJ, TM, TR, UZ. Europe: AL, AM, ES, GR, IT. North Africa: DZ, LY, MA, TN.

General distribution. PAL_SAR_SJP.

Local distribution. MK, QS (Kaszab 1981 1982), RI (Al Dhafer et al. 2016)

Collecting month and method. Frequent species. The adults were collected by HP and PT through II-IV and VI-X. 


\section{Subfamily: Tenebrioninae}

Alphitobius laevigatus (Fabricius, 1781)

World distribution. Africa: GH. Asia: AE, AF, BH, BT, CN, CY, IN, IQ, IR, JP, KZ, RU, SA, TW, YE. Europe: AM, BE, CH, DE, ES, GB, GR, HU, IT, LU, MT, NL, PL, PT, RU, SK, UA. North Africa: EG, ES (Canary Islands), LY, PT (Madeira Archipelago), TN. North America: MX, US.

General distribution. COS (Schawaller 2010).

Local distribution. EP, MD, MK, RI (Kaszab 1979 1982).

Collecting month and method. Very rare species that was collected by LT during X.

Blaps kollari Seidlitz, 1893

World distribution. Asia: AE, IQ, JO, OM, SA, YE. North Africa: EG.

General distribution. SAR.

Local distribution. AS, BA, EP, HA, MD, MK, QS, RI (Kaszab 19791981 1982; El-Hawagry et al. 2013).

Collecting month and method. A frequent species. The adult beetles were collected by HP, LT and PT during I-II, V-VI and X-XII.

Cheirodes brevicollis (Wollaston, 1864)

World distribution. Africa: SO. Asia: AE, AF, BH, CN, EG (Sinai), IL, IQ, IR, JO, KZ, MN, OM, PK, SA, TM, UZ, YE. Europe: ES, IT, MT. North Africa: DZ, EG, ES (Canary Isalands), LY, MA, TN.

General distribution. AFR_PAL_SAR_SJP.

Local distribution. AS, EP, HA, JZ, MD, MK, RI (Kaszab 1979 1982). It is reported as Anemia brevicollis (Wollaston 1864) from BA (El-Hawagry et al. 2013).

Collecting month and method. Common species. The specimens were collected by LT and PT through IV-X.

Cheirodes pilosus (Tournier, 1868)

World distribution. Africa: SD, TD. Asia: AE (Schawaller 2010), EG (Sinai), IL, OM, SA, YE. North Africa: DZ, EG, ES (Canary Isalands), LY, MA, TN.

General distribution. AFR_SAR.

Local distribution. EP, HA, MD, MK, QS, RI (Kaszab 1979 1982).

Collecting month and method. A rare species. The adults were collected by BV and SW on branches of L. shawii and C. procera, respectively during VII; and by LT in V-VI. 
Cheirodes sardous (Gené, 1839)

World distribution. Asia: AE, AZ, CY, EG (Sinai), IL, IQ, IR, JO, SA, TR. Australia: AU. Europe: AM, ES, FR, GR, IT, PT. North Africa: EG, ES (Canary Isalands), LY, MA, TN.

General distribution. AUS_PAL_SAR.

Local distribution. AS, EP, HA, MD, MK, NJ, RI, TB (Kaszab 1979 1982).

Collecting month and method. Very rare species that was collected by LT during VII.

Gonocephalum prolixum (Erichson, 1843)

World distribution. Africa: ZA. Asia: AE, CY, IR, SA, SY. Europe: ES, IT. North Africa: DZ, EG, ES (Canary Isalands), LY, MA, TN.

General distribution. AFR_PAL_SAR.

Local distribution. AS, MD, MK (Kaszab 1979 1982), RI (Al Dhafer et al. 2016).

Collecting month and method. An abundant species. The beetles were collected by HP, LT and PT throughout the year.

Gonocephalum rusticum (Olivier, 1811)

World distribution. Asia: AF, AZ, CN, EG (Sinai), IL, IQ, IR, KZ, MN, OM, RU, SA, TJ, TM, TR, UZ. Europe: AL, AM, ES, FR, GR, HR, IT, MT, MK, PT, RU, UA. North Africa: EG, ES (Canary Isalands), LY, MA, PT (Madeira Archipelago), TN.

General distribution. PAL_SAR_SJP.

Local distribution. AS, EP, MK, RI (Kaszab 1979 1982).

Collecting month and method. Common species that was collected by HP, LT and PT all over the year.

Gonocephalum setulosum (Faldermann, 1837)

World distribution. Africa: ZA. Asia: AE (Schawaller 2010), AF, CN, CY, EG (Sinai), IL, IQ, IR, KZ, LB, SA, SY, TJ, TM, TR, UZ, YE. Europe: AM, ES, GR, IT, MT, RU. North Africa: EG, ES (Canary Isalands), LY, MA, TN.

General distribution. AFR_PAL_SAR_SJP.

Local distribution. EP, HA, MD, MK, QS, RI, TB (Kaszab 1979 1982).

Collecting month and method. Common species that was collected by HP, LT and PT through II, IV-X and XII. 
Gonocephalum soricinum (Reiche \& Saulcy, 1857)

World distribution. Africa: ET. Asia: AE (Schawaller 2010), AF, EG (Sinai), IL, IR, JO, PK, SA, SY, YE.

General distribution. AFR_SAR.

Local distribution. AS, BA, HA, MK, NJ, RI (Kaszab 1979 1982).

Collecting month and method. Rare species that was collected by HP, LT and $\mathrm{PT}$ in I, V and IX-X.

Opatroides vicinus (Fairmaire, 1896)

World distribution. Asia: AE, AF, BH, IN, IR, KW, NP, OM, PK, SA, YE.

General distribution. ORR_SAR.

Local distribution. RI (Kaszab 1979 1982).

Collecting month and method. Abundant species. The specimens of this species were collected by BV on branches of $A$. gerrardii in IV; and by HP, LT and PT throughout the year except in IX and XI.

Palorus ficicola (Wollaston, 1867)

World distribution. Africa: CV, GM. Asia: AE (Schawaller 2010), LK, PK, SA. North Africa: DZ, EG, LY, MA.

General distribution. AFR_ORR_SAR.

Local distribution. MK (Kaszab 1979 1982).

Collecting month and method. Very rare species, which was collected by LT during VIII.

Praeugena gagatina (Mäklin, 1863)

World distribution. Africa: DJ, ER, ET, SD, SN, SO, TD. Asia: AE (Schawaller 2010), SA, YE.

General distribution. AFR_SAR.

Local distribution. AS, JZ, MD, MK, RI (Kaszab 1979 1982).

Collecting month and method. Rare species. The adults were collected by PT under canopy of $L$. shawii during V; and y LT in IV-V.

Prodilamus fausti major Kaszab, 1982

World distribution. Asia: SA. 
General distribution. END.

Local distribution. MD, QS (Kaszab 1982).

Collecting month and method. Very rare species that was collected by HP during XII.

\section{Sclerum carinatum Baudi 1875}

World distribution. Asia: AF, AZ, CY, IQ, IR, SA, SY, TJ, TM, TR, UZ.

General distribution. PAL_SAR.

Local distribution. RI (Kaszab 1979).

Collecting month and method. Rare species that was collected by HP and LT during II-III, VII and IX.

Sclerum orientale (Fabricius, 1775)

World distribution. Africa: SD. Asia: IL, JO, SA, SI, YE. North Africa: EG.

General distribution. AFR_SAR.

Local distribution. RI (Kaszab 1979 1982).

Collecting month and method. A common species. The adult beetles were collected by $\mathrm{BV}$ on branches of $A$. ehrenbergiana during X; and by HP and PT all over the year except in VI and IX.

Sclerum sulcatum Baudi, 1876

World distribution. Asia: SA. North Africa: EG.

General distribution. SAR.

Local distribution. HA, MK, RI (Kaszab 1979 1982; Johnson 1989).

Collecting month and method. A frequent species. The specimens were collected by HP, LT and PT during I-VII, X and XII.

Subfamily: Alluculinae

Cornucistela serrata Campbell, 1980

World distribution. Asia: SA.

General distribution. END.

Local distribution. RI (Campbell 1980).

Collecting month and method. Rare species that was collected by LT during V-VI and VIII-X. 
Cteniopus pallidus (Küster, 1850)

World distribution. Asia: CY, IQ, SY, TR. New to Arabian Peninsula.

General distribution. SAR.

Collecting month and method. Very rare species that was collected by SW during IV.

Hymenalia denticulata (Muche, 1982)

World distribution. Asia: AE, OM, SA.

General distribution. SAR.

Local distribution. AS, BA, MD, MK (Muche 1982).

Collecting month and method. Frequent species. The adults were collected by LT during IV-VI, IX and XI.

Mycetocharina bahukalatensis Novak, 2008

World distribution. Asia: IR. New to Arabian Peninsula

General distribution. SAR.

Collecting month and method. A frequent species that was collected by LT in IV-X.

Mycetocharina braaschi Muche, 1982

World distribution. Asia: AE, SA.

General distribution. SAR.

Local distribution. MK, RI (Muche 1982).

Collecting month and method. Common species. The specimens were collected by LT in IV-VI and X.

Oedemeridae

Subfamily: Oedemerinae

Alloxantha talhouki Švihla, 1984

World distribution. Asia: AE, IR, OM, SA.

General distribution. SAR.

Local distribution. EP (Švihla 1984).

Collecting month and method. Very rare species. The specimens were collected by LT during V-VI. 
Meloidae

Subfamily: Meloinae

Lydomorphus angusticollis suturellus (Haag-Rutenberg, 1880)

World distribution. Asia: AE, IR, OM, PK, SA, YE.

General distribution. SAR.

Local distribution. EP, MD, MK, RI, (Kaszab 1983, Schneider 1991).

Collecting month and method. Very rare species that was collected by LT through IV.

Lydomorphus brittoni (Kaszab 1953)

World distribution. Asia: AE, IQ, OM, SA.

General distribution. SAR.

Local distribution. EP, MD, MK, QS, RI, (Kaszab 1983, Schneider 1991).

Collecting month and method. Frequent species, which was collected by LT during IV.

Lydomorphus palaestinus (Kirsch, 1871)

World distribution. Asia: EG (Sinai), IL, JO, SA. North Africa: DZ, EG, LY, MA, TN. General distribution. SAR.

Local distribution. AS, EP, RI (Kaszab 1983, Schneider 1991).

Collecting month and method. Very rare species that was collected by LT during III.

Subfamily: Nemognathinae

Zonitoschema rubricolor Pic, 1924

World distribution. Africa: CD. Asia: AE (Batelka and Geisthardt 2009), IL, SA.

General distribution. AFR_SAR.

Local distribution. BA, RI (Kaszab 1983, Schneider 1991; El-Hawagry et al. 2013).

Collecting month and method. Very rare species. The adults were collected by LT in VI. 


\section{Anthicidae}

Subfamily: Anthicinae

Anthelephila caeruleipennis (Laferte-Senectere, 1847)

World distribution. Africa: ET, ZA. Asia: AE, EG (Sinai), IL, IQ, IR, JO, LB, OM, PK, SA, SY, YE. Europe: ES, IT. North Africa: DZ, EG, ES (Canary Islands), LY, MA, TN.

General distribution. AFR_SAR.

Local distribution. AS, BA, JZ, MD, MK, QS (Uhmann 1998; El-Hawagry et al. 2013).

Collecting month and method. Very rare species that was collected by LT during IV and VI.

\section{Anthelephila multiformis Kejval, 2002}

World distribution. Asia: AE (Telnov 2007), IR, OM, PK. New to KSA.

General distribution. SAR.

Collecting month and method. Rare species. The specimens of this species were collected by BV, SW, VC and PT on branches/under canopies of $A$. ehrenbergiana, $A$. gerrardii, C. procera, L. shawii, $R$. stricta and $Z$. nummularia; and by LT through IV-VI.

\section{Anthicus crinitus Laferte-Senectere, 1849}

World distribution. Africa: CF, GM, KE, MR, NA, SL, SN, SZ, TD, ZA. Asia: AE, AF, AZ, CN, CY, EG (Sinai), IL, IN, IQ, IR, JO, JP, KW, NP, OM, PK, SA, SY, TH, TR, TW, UZ, YE. Europe: AL, AM, BG, GR, MT, PT, RU. North Africa: DZ, EG, ES (Canary Islands), LY, MA, PT (Madeira Archipelago), TN. North America: CU, DO, PR. South America: VE.

General distribution. COS.

Local distribution. AS, MK, QS, (Uhmann 1998), BA (El-Hawagry et al. 2013), RI (Al Dhafer et al. 2016).

Collecting month and method. Rare species. The adults were collected by PT under canopies of $A$. ehrenbergiana; and by LT during V-VII and IX-X.

\section{Anthicus tristis Schmidt, 1842}

World distribution. Asia: AF, AZ, CY, IL, IQ, IR, JO, KZ, LB, SA, SY, TJ, TM, TR, UZ, YE. Europe: AM, BG, ES, FR, GE, GR, HR, IT, MT, RO, RU, SE, SK, UA. North Africa: DZ, EG, ES (Canary Islands), LY, MA, TN. 
General distribution. PAL_SAR.

Local distribution. RI (Uhmann 1992).

Collecting month and method. Very rare species that was collected by LT in IX.

\section{Endomia lefebvrei (LaFerté-Sénectěre, 1849)}

World distribution. Africa: GM, TD. Asia: AE, AF, CY, EG (Sinai), IL, IQ, IR, JO, OM, QA, SA, TM, TR, YE. North Africa: DZ, EG, LY, MA, TN.

General distribution. AFR_PAL_SAR.

Local distribution. BA (El-Hawagry et al. 2013), JZ, MK (Uhmann 1998), RI (Al Dhafer et al. 2016).

Collecting month and method. A rare species. The beetles were collected by PT under canopies of $A$. gerrardii, C. procera and $R$. stricta; and by LT during IV-VI.

\section{Omonadus floralis (Linnaeus 1758)}

World distribution. Africa: CM, MR, SN, ZA. Asia: AE (Telnov 2007), AF, AZ, BT, CN, CY, EG (Sinai), IL, IN, IR, JO, JP, LB, MN, NP, OM, PK, RU, SA, SY, TM, TR. Australia: PG. Europe: AL, AR, AT, BA, BE, BG, BY, CH, DE, DK, EE, ES, FI, FR, GB, GE, GR, HR, HU, IE, IT, LI, LT, LV, MD, MK, MT, NL, NO, PL, PT, RO, RS, RU, SE, SK, TR, UA. North Africa: DZ, EG, ES (Canary Islands), LY, MA, PT (Madeira Archipelago), TN. North America: CA, US.

General distribution. COS (Uhmann 1998, Telnov 2007).

Local distribution. BA, MK (Uhmann 1998), RI (Alqarni et al. 2015; Al Dhafer et al. 2016).

Collecting month and method. Very rare species that was collected by PT under canopies of $Z$. nummularia, and by LT during V-VI.

\section{Subfamily: Notoxinae}

Mecynotarsus bison (Olivier, 1811)

World distribution. Africa: CG, CI, CV, ET, SD, SO, TD, TZ. Asia: AE, CY, EG (Sinai), IL, IQ, IR, LB, SA, TR, YE. Europe: GR. North Africa: DZ, EG, ES (Canary Islands), LY, MA, TN.

General distribution. AFR_PAL_SAR.

Local distribution. EP, JZ, MD, MK, NB, RI, TB (Uhmann 1998).

Collecting month and method. Very rare species that was collected by PT under canopy of $R$. stricta in IV. 


\section{Scraptiidae}

Subfamily: Anaspidinae

Pentaria arabica Pankow, 1981

World distribution. Asia: SA.

General distribution. END.

Local distribution. AS (Pankow 1981).

Collecting month and method. A frequent species. It was collected by BV and PT on branches/under canopy of A. ehrenbergiana, and by LT and MT through IV-V, VII and X.

\section{Pentaria sp.}

Collecting month and method. Rare species. The specimens were collected by BV on branches of $Z$. nummularia in V, by PT under canopy of $L$. shawii in V, and by LT during V-VII and IX.

\section{Cerambycidae}

Subfamily: Prioninae

Polyarthron philbyi Villiers, 1968

World distribution. Asia: SA.

General distribution. END.

Local distribution. RI (Holzschuh 1993).

Collecting month and method. Very rare species. It was collected by HP during IX.

\section{Subfamily: Lamiinae}

Apomecyna lameerei (Pic, 1895)

World distribution. Africa: MR. Asia: AE, IL, IQ, IR, PK, SA. North Africa: EG.

General distribution. AFR_SAR.

Local distribution. MD, MK, RI (Holzschuh and Téocchi 1991).

Collecting month and method. Rare species. The adults were collected by HP and LT during IV-V, X-XI. 


\section{Chrysomelidae}

Subfamily: Bruchinae

Bruchidius centromaculatus (Allard, 1868)

World distribution. Africa: BF, CD, MR, SD, SN. Asia: IL, SA, YE. North Africa: EG. General distribution. AFR_SAR.

Local distribution. AS (Anton 1994), RI (Al Dhafer et al. 2016).

Collecting month and method. Common species, which was collected by BV, SW and VC on branches of A. ehrenbergiana, A. gerrardii, C. procera, L. shawii, $R$. stricta and $Z$. nummularia, and by HP, LT and PT throughout the year.

Careydon acaciae (Gyllenhall, 1833)

World distribution. Africa: AO, BF, CD, CM. ET, KE, MR, MZ, NA, NE, NG, RW, SD, SN, SO, SZ, TD, TZ, ZA. Asia: IR, JO, SA, YE. Europe: ES, HU. North Africa: EG.

General distribution. AFR_SAR.

Local distribution. AS, MK (Decelle 1979), RI (Al Dhafer et al. 2016)

Collecting month and method. Common species. The specimens were collected by PT under the canopies of $A$. ehrenbergiana, A. gerrardii, C. procera and L. shawii; and by SW on branches of $C$. procera and $R$. stricta; and by HP, LT and MT throughout the year.

Spermophagus sericeus (Geoffory, 1785)

World distribution. Asia: AF, AZ, CN, CY, IL, IQ, IR, JO, KG, KZ, LB, MN, SA, SY, TJ, TM, TR, UZ. Europe: AL, AM, AT, BA, BE, BG, CH, CZ, DE, DK, ES, FI, FR, GB, GE, GR, HR, HU, IT, LU, MK, MT, NL, PL, PT, RO, RS, RU, SE, SI, SK, UA. North Africa: DZ, MA, TN.

General distribution. PAL_SAR_SJP.

Local distribution. RI (Anton 1994).

Collecting month and method. Very rare that species was collected by SW on branches of $C$. procera during VIII.

Subfamily: Chrysomelinae

Colaphellus apicalis (Ménétriés, 1849)

World distribution. Asia: AF, IL, IR, KG, KZ, SY, TM, TR, UZ. New to Arabian Peninsula. 
General distribution. PAL_SAR.

Collecting month and method. Very rare species. It was collected by PT under the canopy of $R$. stricta during II.

\section{Subfamily: Galerucinae}

Phyllotreta lativittata Kutschera, 1860

World distribution. Asia: AF, AZ, CN, CY, IL, IQ, IR, JO, KG, KZ. LB, OM, RU, SA (Al Dhafer et al. 2016), SY, TJ, TR, TM, UZ. Europe: AM, GR, IT, MT.

General distribution. PAL_SAR_SJP.

Local distribution. RI (Al Dhafer et al. 2016).

Collecting month and method. Common species. The adult beetles were collected by BV, SW, VC and PT on branches/under the canopies of $A$. ehrenbergiana, A. gerrardii, C. procera, L. shawii. R. stricta and Z. nummularia; and by LT and MT throughout the year.

Psylliodes peyerimboffi Heikertinger, 1916

World distribution. Asia: AE, EG (Sinai), SA.

General distribution. SAR.

Local distribution. RI (Doguet 1979; Medvedev 1996).

Collecting month and method. Very rare species that was collected by LT during IV.

Subfamily: Cryptocephalinae

Aetheomorpha seminigra pumilio (Lacordaire 1848)

World distribution. Africa: ET, SD. Asia: AF, JO, OM, SA, YE. North Africa: EG.

General distribution. AFR_SAR.

Local distribution. AS, BA, JZ, MK (Medvedev 1993 1996; El-Hawagry et al. 2013).

Collecting month and method. Very rare species, which was collected by BV on branches of $A$. gerrardii during $\mathrm{V}$.

Subfamily: Eumolpinae

Macrocoma lefevrei (Baly, 1878)

World distribution. Asia: IR, OM, SA. North Africa: EG. 
General distribution. SAR.

Local distribution. MK (Medvedev 1996).

Collecting month and method. Very rare species. It was collected by LT during IV.

\section{Brentidae}

Subfamily: Apioninae

Aplemonus arabicus (Wagner, 1909)

World distribution. Africa: MW, ZA. Asia: AE (Magnano et al. 2009), IR, OM, QA (Magnano et al. 2009), SA (Al Dhafer et al. 2016). North Africa: EG.

General distribution. AFR_SAR.

Local distribution. RI (Al Dhafer et al. 2016)

Collecting month and method. Common species. The beetles of this species were collected by BV, SW and VC on branches of A. ehrenbergiana, A. gerrardii, L. shawii and $Z$. nummularia; by PT under canopies of $C$. procera; and by LT throughout the year.

Subfamily: Nanophyinae

Allomalia quadrivirgata (A. Costa, 1863)

World distribution. Asia: AZ, CY, IL, KZ, SA (Abdel-Dayem et al. 2015), SY, UZ. Europe: BG, ES, FR, GE, GR, HR, HU, IT, UA. North Africa: DZ, EG, LY, MA, TN.

General distribution. PAL_SAR.

Local distribution. RI (Abdel-Dayem et al. 2015).

Collecting month and method. Very rare species that was collected by BV on branches of $Z$. nummularia in IV.

Curculionidae

Subfamily: Curculioninae

Assuanensius discoidalis (Tournier, 1873)

World distribution. Africa: TD. Asia: IL, SA (Abdel-Dayem et al. 2015). North Africa: DZ, EG, LY, MA.

General distribution. AFR_SAR.

Local distribution. RI (Abdel-Dayem et al. 2015).

Collecting month and method. Common species. The specimens were collected by $\mathrm{BV}$ on branches of $A$. ehrenbergiana in III-V. 
Assuanensius erectesetosus (Peyerimhoff, 1948)

World distribution. Africa: TD. Asia: IL, SA (Abdel-Dayem et al. 2015). North Africa: EG, LY, MA.

General distribution. AFR_SAR.

Local distribution. RI (Abdel-Dayem et al. 2015).

Collecting month and method. Very rare species. The beetles were collected by $\mathrm{BV}$ on branches of $A$. ehrenbergiana, A. gerrardii, C. procera, L. shawii, R. stricta and $Z$. nummularia during I-VII and IX; by PT under canopies of $C$. procera and $R$. stricta in III; and by HP and SW in II and III respectivelly.

\section{Assuanensius peyerimhoffi (Hoffmann, 1963)}

World distribution. Africa: TD. Asia: SA (Abdel-Dayem et al. 2015). North Africa: DZ, LY.

General distribution. AFR_SAR.

Local distribution. RI (Abdel-Dayem et al. 2015).

Collecting month and method. A frequent species. The specimens were collected by $\mathrm{BV}$ on branches of $A$. ehrenbergiana, $A$. gerrardii and $Z$. nummularia during I-III, V, VIII, and IX-XII.

Mecinus longulus (Desbrochers des Loges, 1893)

World distribution. Asia: IL, SA (Abdel-Dayem et al. 2015). North Africa: DZ, EG, LY, TN.

General distribution. SAR.

Local distribution. RI (Abdel-Dayem et al. 2015).

Collecting month and method. Very rare species that was collected by BV on branches of $L$. shawii and by PT under canopy of C. stricta during III.

Pachytychius cognatus Caldara, 2000

World distribution. Africa: AO, DJ, SD, SN. Asia: SA, YE.

General distribution. AFR_SAR.

Local distribution. JZ (Caldara 2000).

Collecting month and method. Very rare species, which was collected by PT under canopy of C. stricta in XII. 
World distribution. Africa: SD. Asia: SA (Abdel-Dayem et al. 2015), TR. North Africa: DZ, EG, LY, MA, TN.

General distribution. AFR_SAR.

Local distribution. RI (Abdel-Dayem et al. 2015).

Collecting month and method. Very rare species that was collected by PT under canopy of $Z$. nummularia during IV.

Sharpia sabulicola Colonnelli, 2009

World distribution. Asia: AE (Magnano et al. 2009), SA (Abdel-Dayem et al. 2015). General distribution. SAR.

Local distribution. RI (Abdel-Dayem et al. 2015).

Collecting month and method. Very rare species and its adult was collected by LT during IV.

\section{Sharpia soluta Faust, 1885}

World distribution. Asia: AE (Magnano et al. 2009), AZ, CY, SA (Abdel-Dayem et al. 2015), TM, UZ. Europe: RO.

General distribution. PAL_SAR.

Local distribution. RI (Abdel-Dayem et al. 2015).

Collecting month and method. Rare species. It was collected by PT under canopies of $A$. ehrenbergiana, $C$. procera, $R$. stricta, and $Z$. nummularia during III-IV, X and XII; also collected by LT during V.

Sphincticraerus bruleriei (Desbrochers des Loges, 1873)

World distribution. Asia: IL, SA (Abdel-Dayem et al. 2015). North Africa: EG.

General distribution. SAR.

Local distribution. RI (Abdel-Dayem et al. 2015).

Collecting month and method. A rare species. The adult beetles were collected by $\mathrm{BV}$ on branches of $Z$. nummularia during II and V; and by LT through X.

Tychius banfii Caldara \& Fremuth, 1992

World distribution. Asia: IQ, IR, JO, SA, TR. North Africa: EG.

General distribution. PAL_SAR. 
Local distribution. EP, RI (Caldara 1993).

Collecting month and method. Rare species. Its adult was collected by BV on branches of $A$. ehrenbergiana, $A$. gerrardii and $Z$. nummularia through XII; by PT under canopy of $A$. ehrenbergiana in XI; and by LT and MT during V and VII respectivelly.

Tychius mozabitus Pic, 1898

World distribution. Asia: EG (Sinai), IQ, IR, JO, SA. North Africa: DZ, EG, LY, TN.

General distribution. SAR.

Local distribution. MD, RI (Caldara 1993).

Collecting month and method. Very rare species that was collected by PT under canopy of $C$. procers in II.

Tychius vicinus Roudier, 1954

World distribution. Asia: AE (Magnano et al. 2009), SA, YE. North Africa: DZ, EG. General distribution. SAR.

Local distribution. AS, RI (Caldara 1993).

Collecting month and method. A frequent species. The adults were collected by $\mathrm{BV}, \mathrm{SW}$ and VC on branches of $A$. gerrardii, R. stricta and Z. nummularia during III$\mathrm{V}$; and by PT under canopy of $A$. ehrenbergiana during I-VI and XII.

\section{Subfamily: Entiminae}

Myllocerus sp.

Collecting month and method. A rare species. It was collected by PT under canopies of $R$. stricta and Z. nummularia during I-II; and by HP and LT in I, IV and XII.

\section{Tanymecus musculus Fåhraeus, 1840}

World distribution. Asia: IL, IQ, SA (Abdel-Dayem et al. 2015), SY. North Africa: EG. General distribution. SAR.

Local distribution. RI (Abdel-Dayem et al. 2015).

Collecting month and method. Very rare species that was collected by LT in I, IV and XII. 


\section{Subfamily: Hyperinae}

Brachypera isabellina (Boheman, 1834)

World distribution. Asia: AE (Magnano et al. 2009), IL, IQ, IR, JO, KW, QA, SA, SY, TR. Europe: IT (Sicilia). North Africa: DZ, EG, ES (Canary Islands), LY, MA, PT (Madeira Archipelago), TN.

General distribution. SAR.

Local distribution. Heyden (1913) just mentioned Arabia without any further detail about locality. Abdel-Dayem et al. (2015) have been confirmed the occurrence of the species in KSA: RI.

Collecting month and method. A rare species. The beetles were collected by PT under canopies of $C$. procera, $R$. stricta and $Z$. nummularia during II, VIII and XII.

Hypera brunnipennis (Boheman, 1834)

World distribution. Asia: IL, IR, LB, SA (Abdel-Dayem et al. 2015). North Africa: EG. North America: US.

General distribution. NAR_SAR.

Local distribution. RI (Abdel-Dayem et al. 2015).

Collecting month and method. Very rare species that was collected by LT during IV.

Subfamily: Lixinae

Hypolixus pica (Fabricius, 1798)

World distribution. Africa: CG, ET, NE, SN, TD, TG. Asia: AE, CY, ID, IQ, IR, JO, PK, SA (Abdel-Dayem et al. 2015), SY, TR, YE (Socotra). Europe: FR. North Africa: EG.

General distribution. AFR_PAL_SAR.

Local distribution. RI (Abdel-Dayem et al. 2015).

Collecting month and method. Very rare species that was collected by BV on branches of $A$. ehrenbergiana in XI.

Larinus elegans Desbrochers des Loges, 1897

World distribution. Asia: SA. North Africa: DZ, EG, LY, MA.

General distribution. SAR.

Local distribution. There is no available information.

Collecting month and method. Very rare species. The adult of this species was collected by BV on branches of $Z$. nummularia through $\mathrm{V}$. 


\section{Lixus ?subfarinosus Desbrochers des Loges, 1893}

World distribution. Asia: AE, IQ, SA (Abdel-Dayem et al. 2015), TR, YE. North Africa: EG. TN.

General distribution. SAR.

Local distribution. RI (Abdel-Dayem et al. 2015).

Collecting month and method. Very rare species that was collected by HP in IV.

\section{Pycnodactylopsis tomentosa (Fåhraeus, 1842)}

World distribution. Africa: ET, MR, SD, TD. Asia: EG (Sinai), IL, IN, IQ, IR, JO, PK, SA, YE. North Africa: DZ, EG, ES (Canary Islands), LY, MA, TN.

General distribution. AFR_ORR_SAR.

Local distribution. RI (Shalaby 1961, Beccari 1971).

Collecting month and method. Very rare species that was collected by HP in II.

\section{Acknowledgments}

We would like to thank the following specialists for their help in identification or confirmation of the identification: David Král (Charles University in Prague, Faculty of Science, Department of Zoology, Czech Republic), Enzo Colonnelli, (Via delle Giunchiglie, 5600172 Roma, Italy), Giuseppe Platia (Via Molino Vecchio, Gatteo (FC), Italy), Jan Bezděk (Mendel University, Department of Zoology, Zemědělská, Czech Republic); Lev Medvedev (Institute of Animal Morphology and Ecology, Leninsky Prospect, Moscow, Russia), Ron Felix (Naturalis Biodiversity Center Leiden, The Netherland), Tomas Lackner (Munich State Museum, Munich, Germany), and Wolfgang Schawaller (Staatliches Museum für Naturkunde, Stuttgart, Germany). The authors would like to extend their sincere appreciation to the Deanship of Scientific Research at King Saud University for its funding this research group NO (RGP-1437-009).

\section{References}

Abdel-Dayem MS, Colonnelli E, Fadl HH, Al Dhafer HM (2015) New records of Curculionoidea (Coleoptera) from the Kingdom of Saudi Arabia. The Coleopterists Bulletin 69(4): 639-644. doi: http://dx.doi.org/10.1649/0010-065X-69.4.639

Abdel-Dayem MS, Kondratieff BC, Fadl HH, Al Dhafer HM (2016) Dung beetle (Coleoptera, Scarabaeidae) abundance and diversity at nature preserve within hyper-arid ecosystem of Arabian Peninsula. Annals of the Entomological Society of America 109(2). https://doi. org/10.1093/aesa/sav154 
Ahrens D (2000) Sericinae (Coleoptera: Scarabaeoidea: Melolonthidae) of Arabia. Fauna of Arabia 18: 177-210.

Al Dhafer HM, Abdel-Dayem MS, Aldryhim YN, Fadl HH, El-Torkey AM, Elgharbawy AA, Setyaningrum H (2016) Diversity and composition of ground-dwelling beetle assemblages (Insecta: Coleoptera) in Rawdhat Khorim National Park, Kingdom of Saudi Arabia. Journal of Arid Environments 127: 187-191. http://dx.doi.org/10.1016/j.jaridenv.2015.11.007

Al Dhafer HM, Platia G (2013) Contribution to the knowledge of the genus Dicronychus (Coleoptera: Elateridae) from the Kingdom of Saudi Arabia. Zootaxa 3734(1): 15-22. https:// doi.org/10.11646/zootaxa.3734.1.2

Alfarhan AH (2001) A floristic account on Raudhat Khuraim Central Province Saudi Arabia. Saudi Journal of Biological Sciences 8: 80-103.

Alqarni AS, Awad AM, Raweh HSA, Owayss AA (2015) Pollination ecology of Acacia gerrardii Benth. (Fabaceae: Mimosoideae) under extremely hot-dry conditions. Saudi Journal of Biological Sciences. http://dx.doi.org/10.1016/j.sjbs.2015.09.019

Al-Ahmadi AZ, Salem MM (1999) Entomofauna of Saudi Arabia, General survey of insects reported in the Kingdom of Saudi Arabia. Part I: Checklist of insects. King Saud University, Academic publishing and press, Riyadh, Saudi Arabia, 240 pp.

Al-Farraj MM, Alfarhan A, Al-Yemeni M (1997) Ecological studies on Rawdhat system in Saudi Arabia I- Rawdhat Khorim. Pakistan Journal of Botany 29: 75-88.

Al-Nafie AH (2007) The effect of off-road driving on the plant cover of natural recreational areas in Central of Saudi Arabia. Saudi Journal of Biological Sciences 14: 53-72.

Al-Qarawi AA (2011) Vegetation analysis in the Rawdhat Om Al-Khefas, Central Saudi Arabia. Australian Journal of Basic and Applied Sciences 5(12): 3264-3269.

Anton K-W (1994) The Bruchidae (Coleoptera) of Saudi Arabia, with description of two new species. Fauna of Saudi Arabia 14: 97-104.

Bale JS, Masters GJ, Hodkinson ID, Awmack C, Bezemer TM, Brown VK, Butterfield J, Buse A, Coulson JC, Farrar J, Good JE (2002) Herbivory in global climate change research: direct effects of rising temperature on insect herbivores. Global Change Biology 8(1): 1-16. https://doi.org/10.1046/j.1365-2486.2002.00451.x

Balkenohl M (1994) The Subfamily Scaritinae Bonelli, 1809 (Coleoptera: Carabidae) from Arabia. Fauna of Saudi Arabia 14: 59-70.

Ball G, Shpeley D (2005) Taxonomic review of the Tribe Melaenini (Coleoptera: Carabidae), with observations on morphological, ecological and chorological evolution. Zootaxa 1099: $1-120$.

Balthasar V (1972) Coleopteraous Nordostafrica, Scarabaeoidae: Scarabaeidae und Aphdiidae. NotulaeEntomologicae 52: 18-32.

Basilewsky P (1979) Insect of Saudi Arabia, Coleoptera: Fam. Carabidae. Fauna of Saudi Arabia 1: 141-146.

Batelka J, Geisthardt M (2009) Order Coleoptera, family Meloidae. Arthropod fauna of the UAE 2: 187-206.

Beccari F (1971) Contribution alla conoscenze d'ell' entomofauna dell' Arabia Saudita. Primo elenco di insetti acari e nematode. Rivista di Agricolatura Subtropical et Tropicale 65: 243-258. 
Besuchet C (1981) Insects of Saudi Arabia. Coleoptera: Fam. Pselaphidae. Fauna of Saudi Arabia 3: 243-250.

Besuchet C, Cuccodoro G (2011) Order Coleoptera, family Staphylinidae, Subfamily Pselaphinae. Arthropod fauna of the UAE 4: 151-167.

Bílý S (1979) Insects of Saudi Arabia, Coleoptera: Fam. Buprestidae. Fauna of Saudi Arabia 1: 215-222.

Bílý S (1980) Insects of Saudi Arabia, Coleoptera: Fam. Buprestidae (Part 2). Fauna of Saudi Arabia 2: 119-121.

Bílý S (1982) Insects of Saudi Arabia, Coleoptera: Fam. Buprestidae (Part 3). Fauna of Saudi Arabia 4: 111-115.

Bílý S (1985) Coleoptera: Fam. Buprestidae of Saudi Arabia (Part 4). Fauna of Saudi Arabia 7: 160-164.

Bouchard P, Bousquet Y, Davies AE, Alonso-Zarazaga MA, Lawrence JF, Lyal CHC, Newton AF, Reid CAM, Schmitt M, Ślipiński A, Smith ABT (2011) Family-group names in Coleoptera (Insecta). Zookeys 88: 1-972. https://doi.org/10.3897/zookeys.88.807

Brancucci M (1979) Insects of Saudi Arabia, Coleoptera: Fam. Haliplidae, Dytscidae, Gyrinidae. Fauna of Saudi Arabia 1: 156-161.

Brancucci M (1984) Insects of Saudi Arabia, Coleoptera: Fam. Haliplidae, Noteridae, Dytscidae, Gyrinidae (Part 4). Fauna of Saudi Arabia 6: 229-242.

Britton EB (1948) Coleoptera: Cicindelidae and Carabidae from Southern Arabia. Expedition to South-west Arabia 1937-8 (Vol. 1). British Museum of Natural History, London, $87-125$.

Caldara R (1993) The Subfamily Tychiinae (Coleoptera: Curculionidae) from Saudi Arabia. Fauna of Saudi Arabia 13: 137-143.

Caldara R (2000) Revisione dei Pachytychius delle Regioni Afrotropicale e Orientale (Coleoptera, Curculionidae). Memorie della Societá Entomologica Italiana 78(1): 131-166.

Campbell JM (1980) Insects of Saudi Arabia, Coleoptera: Fam. Alleculidae. Fauna of Saudi Arabia 2: 133-136.

Cassola F and Schneider W. (1997) Tiger Beetles (Coleoptera: Cicindelidae) from the Saudi Arabian Gulf coast. Fauna of Saudi Arabia 16: 247-253.

Chassain J (1979) Insects of Saudi Arabia, Coleoptera: Fam. Elateridae. Fauna of Saudi Arabia 1: $193-211$.

Chassain J (1983) Insect of Saudi Arabia, Coleoptera: Fam. Elateridae (2 ${ }^{\text {nd }}$ Part). Fauna of Saudi Arabia 5: 129-143.

Cobos A (1963) Cuatro Buprestidos nuevos de Oriente Medio (Coleoptera). FOS, Revista Espanoia de Entomologia 39: 357-365.

Damoiseau R (1979) Insects of Saudi Arabia, Coleoptera: Fam. Bostrichidae. Fauna of Saudi Arabia 1: 249-250.

Decelle J (1979) Insects of Saudi Arabia, Coleoptera: Fam. Bruchidae. Fauna of Saudi Arabia 1: 318-330.

Doguet S (1979) Insects of Saudi Arabia, Coleoptera: Fam. Chrysomelidae, Subfam. Halticinae. Fauna of Saudi Arabia 1: 308-316. 
El-Hawagry MS, Khalil MW, Sharaf MR, Fadl HH, Aldawood AS (2013) A preliminary study on the insect fauna of Al-Baha Province, Saudi Arabia, with descriptions of two new species. ZooKeys 274: 1-88. https://doi.org/10.3897/zookeys.274.4529

Emden FJ v (1954) The $3^{\text {rd }}$ Danish expedition to Central Asia. Zoological results 13. Carabidae (Insecta) from Afghanistan (exclusive of Cicindelinae). Vidensk Medd fra Dansk naturh Foren 116: 175-188.

Endrődi S (1980) Insects of Saudi Arabia, Coleoptera: Fam. Scarabaeidae, Subf. Dynastinae. Fauna of Saudi Arabia 2: 157-158.

Endrödy-Younga S (1979) Insects of Saudi Arabia, Coleoptera: Fam. Cybocephalidae. Fauna of Saudi Arabia 1: 228-231.

Felix RFFL (2009) Order Coleoptera, family Carabidae. Arthropod fauna of the UAE 2: 66-141. Fürsch H (1979) Insects of Saudi Arabia, Coleoptera: Fam. Coccinellidae. Fauna of Saudi Arabia 1: 235-248.

Fürsch H (1989) The Arabian species of the Scymnus (Pullus) guimeti-group (Coleoptera, Coccinellidae). Fauna of Saudi Arabia 10: 113-122.

Geistharde M (2010) Order Coleoptera, Family Bostrichidae. Arthropod fauna of the UAE 3: 204-225.

Gerstmeier R (2010) Order Coleoptera, Family Cleridae. Arthropod fauna of the UAE 3: 226-239.

Hájek J and M. Brancucci. (2011) Order Coleoptera, family Dytiscidae. Arthropod fauna of the UAE 4: 126-143.

Hammond PM (1992) Species inventory. In: Groombridge B (Ed.) Global Biodiversity, Status of the Earth's Living Resources. Chapman and Hall, London, 17-39. https://doi. org/10.1007/978-94-011-2282-5_4

Háva J (2003) World Catalogue of the Dermestidae (Coleoptera). Studie a Zprávy Oblastního Muzea Praha-východ v Brandýse nad Labem a Staré Boleslavi Supplementum 1: 1-196.

Háva J (2009) Order Coleoptera, family Dermestidae. Arthropod fauna of the UAE 2: 164-173. Háva J (2013) Second contribution to knowledge of Dermestidae (Coleoptera: Bostrichoidea) from the United Arab Emirates. Studies and Reports, Taxonomical Series 9(1): 51-60.

Heinertz R (1979) Insect of Saudi Arabia, Coleoptera: Fam. Carabidae. Fauna of Saudi Arabia 1: 140 .

Heyden L (1913) Die Coleopteren-Ausbeute des Dr. Ernst Hartert aus der Centralen WestSahara (1912) Novitates Zoologicae 20:85-108.

Hieke F (1993) Die Untergattung Harpalodema Reitter, 1888, von Amara Bon. sowie über Amara-Arten anderer Subgenera. (Coleoptera, Carabidae). Deutsche Entomologische Zeitschrift 40(1): 1-160. https://doi.org/10.1002/mmnd.19930400102

Holt BG, Lessard JP, Borregaard MK, Fritz SA, Araújo MB, Dimitrov D, Fabre P-H, Graham CH, Graves GR, Jønsson KA, Nogués-Bravo D, Wang Z, Whittaker RJ, Fjeldså J, Rahbek C (2013) An update of Wallace's zoogeographic regions of the world. Science 339(6115): 74-78. https://doi.org/10.1126/science.1228282

Holzschuh C (1993) Cerambycidae (Coleoptera) of Saudi Arabia: Part II, Prioninae and Cerambycinae. Fauna of Saudi Arabia 13: 110-129. 
Holzschuh, C \& Téocchi P (1991) Cerambycidae (Coleoptera) of Saudi Arabia: Part I, Lamiinae. Fauna of Saudi Arabia 12: 295-311.

Huffaker CB, Gutierrez AP (1999) Ecological Entomology. John Wiley \& Sons, Canada, $2^{\text {nd }}$ edition, $756 \mathrm{pp}$.

Hunt T, Bergsten J, Levkanicova Z, Papadopoulou A, John OS, Wild R, Hammond PM, Ahrens D, Balke M, Caterino MS, Gómez-Zurita J, Ribera I, Barraclough TG, Bocakova M, Bocak L, Vogler AP et al. (2007) "A Comprehensive Phylogeny of Beetles Reveals the Evolutionary Origins of a Superradiation”. Science 318(5858): 1913-1916. https://doi. org/10.1126/science.1146954

Jelinek J (1979) Insect of Saudi Arabia. Coleoptera: Fam. Nitidulidae. Fauna of Saudi Arabia 1: 223-227.

Jelinek J (1988) Coleoptera: Nitidulidae of Saudi Arabia (Part 2). Fauna of Saudi Arabia 9: 42-51. Johnson C (1989) Tenebrionidae (Coleoptera) collected in the Eastern Province of Saudi Arabia. Fauna of Saudi Arabia 10: 123-133.

Kanaar P (2007) Order Coleoptera, family Histeridae. Arthropod fauna of the UAE 1: 170-193. Kaszab Z (1979) Insects of Saudi Arabia, Coleoptera: Fam. Tenebrionidae. Fauna of Saudi Arabia 1: 257-288.

Kaszab Z (1981) Insects of Saudi Arabia. Coleoptera: Fam. Tenebrionidae (Part 2). Fauna of Saudi Arabia, 3: 276-401.

Kaszab Z (1982) Insect of Saudi Arabia, Coleoptera: Fam. Tenebrionidae (Part 2). Fauna of Saudi Arabia 4: 124-243.

Kaszab Z (1983) Insect of Saudi Arabia. Coleoptera: Fam. Meloidae. A synopsis of The Arabian Meloidae. Fauna of Saudi Arabia 5: 144-204.

Kerremans C (1913) Monnographie des buprestides - Tome.VI Sphenoptera (pars). A. Breuer, Bruxelles, 97-595.

Král D and Batelka J (2015) Order Coleoptera, superfamily Scarabaeoidea. Arthropod fauna of the UAE, 6. [In press]

Kryzhanovskij O (1979) Insect of Saudi Arabia. Coleoptera: Fam. Histeridae. Fauna of Saudi Arabia 1: 184-185.

Kuijten PJ (1980) Insects of Saudi Arabia, Coleoptera: Fam. Scarabaeidae. Subfam. Hybosorinae. Fauna of Saudi Arabia 2: 155-156.

Lackner T (2014) Revision of the genus Reichardtiolus Kryzhanovskij, 1959 (Coleoptera, Histeridae, Saprininae). ZooKeys 379: 1-27. https://doi.org/10.3897/zookeys.379.6457

Löbl I, Merkl O, Ando K, Bouchard P, Lillig M, Masomuto K, Schawaller W (2008) Family Tenebrionidae Latreille, 1802. In: Löbl I, Smetana A (Eds) Catalogue of Palaeartic Coleoptera, Tenebrionoidea, Volume 5. Apollo Books, Stenstrup, 105-352.

Magnano LE, Colonelli, Caldara R (2009) Order Coleoptera, superfamily Curculionoidea. Arthropod fauna of the UAE 2: 216-266.

Mascagni A (2009) Order Coleoptera, family Heteroceridae. Arthropod fauna of the UAE 2: 154-158.

Mateu J (1979) Insect of Saudi Arabia, Coleoptera: Fam. Carabidae, Subfam. Lebiinae. Fauna of Saudi Arabia 1: 147-155. 
Mateu J (1986) Lebiinae and Brachininae of Saudi Arabia (Coleoptera: Carabidae). Lebiinae. Fauna of Saudi Arabia 8: 198-218.

Mazur S (1994) Histeridae (Coleoptera) of the Arabian Peninsula. Fauna of Saudi Arabia 14: $71-76$.

Medvedev L (1993) Further records of Clytrinae (Coleoptera: Chrysomelidae) from Arabia. Fauna of Saudi Arabia 13: 131-136.

Medvedev L (1996) The Chrysomelidae of Arabia. Fauna of Saudi Arabia 15: 211-263.

Menier JJ (1986) Coleoptera: Fam. Cleridae of Saudi Arabia (Part 2). Fauna of Saudi Arabia 8: 219-232.

Mroczkowski M (1979) Insect of Saudi Arabia, Coleoptera: Fam. Dermestidae. Fauna of Saudi Arabia 1: 212-214.

Mroczkowski M (1980) Insect of Saudi Arabia, Coleoptera: Fam. Dermestidae, Part 2, Description of three new species. Fauna of Saudi Arabia 2: 124-126.

Muche WH (1982) Insect of Saudi Arabia, Coleoptera: Fam. Alleculidae. Fauna of Saudi Arabia 4: 116-123.

Otero JC (2013) Cryptophaginae (Coleoptera) de la Región Paleártica Occidental. Coleopterological Monographs (Vol. 4). European Association of Coleopterology, Barcelona, 295 pp.

Pankow W (1981) Insect of Saudi Arabia, Coleoptera: Fam. Mordellidae and Scraptiidae, Subfam. Anaspidinae. Fauna of Saudi Arabia 3: 273-275.

Paulian R (1980) Insects of Saudi Arabia, Coleoptera: Fam. Scarabaeidae (1 $1^{\text {re }}$ contribution). Fauna of Saudi Arabia 2: 141-154.

Penati F, Vienna P (2006) An updated catalogue of the Histeridae (Insecta: Coleoptera) of the Arabian Peninsula, with biogeographical remarks. Zootaxa 1157: 1-74.

Pittino R (1984) Insects of Saudi Arabia. Coleoptera Scarabaeoidea: A Revision of the Family Aphodiidae. Fauna of Saudi Arabia, 6: 267-360.

Platia G (2007) Order Coleoptera, family Elateridae. Arthropod fauna of the UAE 1: 194-210.

Platia G (2012) Description of ten new species of click beetles from the Palearctic region with new distributional records (Coleoptera, Elateridae). Boletín de la Sociedad Entomológica Aragonesa (SEA) 50: 199-207.

Platia G and Schimmel R (1997) Click-beetles (Coleoptera: Elateridae) from the Sultanate of Oman with additional new species and records from neighbouring regions. Fauna of Saudi Arabia 16: 291-318.

Raimundo AC, Fürsch H, van Harten A (2007) Order Coleoptera, family Elateridae. Arthropod fauna of the UAE 1: 217-239.

Rosenzweig ML (1995) Species Diversity in Space and Time. Cambridge University Press. https://doi.org/10.1017/CBO9780511623387

Sabatinelli G, Pontuale G (1998) Melolonthinae and Pachydeminae of Arabia (Coleoptera: Scarabaeoidea: Melolonthidae). Fauna of Arabia 17: 107-146.

Schatzmayr A (1936) Risultati scientifici della spedizione entomologica di S.A.S. il Principe Alessandro della Torre e Tasso in Egitto e nella penisola del Sinai. XII. Catalogo agionato dei Carabidi finora noti d'Egitto e del Sinai. Pubblicazioni del Museo entomologico Pietro Rossi 14(1): 1-114. 
Schawaller W (2010) Order Coleoptera, family Tenebrionidae (with exception of the subfamily Alleculinae). Arthropod fauna of the UAE 3: 253-278.

Schawaller W, Al Dhafer HM, Fadl HH (2013) Boromorphus saudicus sp. n., a new record of the genus from the Arabian Peninsula (Tenebrionidae: Pimeliinae: Boromorphini), Zoology in the Middle East 59(2): 148-151. https://doi.org/10.1080/09397140.2013.810878

Schneider W (1991) New records of Meloidae (Insecta: Coleoptera) from Arabia with Description of a new species. Fauna of Saudi Arabia 12: 273-288.

Shalaby F (1961) A preliminary survey of the insect fauna of Saudi Arabia. Bull. Soc. ent. Egypte 45: 211-228.

Sharaf MR, Abdel-Dayem MS, Al Dhafer HM, Aldawood AS (2013) The ants (Hymenoptera: Formicidae) of Rawdhat Khorim Nature Preserve, Saudi Arabia, with description of a new species of the genus Tetramorium Mayr. Zootaxa 3709(6): 565-580. https://doi. org/10.11646/zootaxa.3709.6.6

Stack C (2015) Beetles: Biodiversity, Ecology and Role in the Environment. Nova Science Pub Incorporated, New York, 250 pp.

Švec Z (2010a) Coleoptera, family Leiodidae. Arthropod fauna of the UAE 3: 195-203.

Švec Z (2010b) Order Coleoptera, family Phalacridae. Arthropod fauna of the UAE 3: 249-252.

Švihla V (1984) Insect of Saudi Arabia, Coleoptera: Fam. Oedemeridae (Part 2). Fauna of Saudi Arabia 6: 260-266.

Tag El-din S, Assaeed A and Al-Sheick A (1994) Distribution of range plant communities as influenced by edaphic factors in Raudhat Khuraim. Egyptian Journal of Applied Sciences 9: 69-82.

Talhouk AS (1982) Applied Zoology in Saudi Arabia. A note on the entomophagous fauna of Saudi Arabia. Fauna of Saudi Arabia 4: 525-531.

Telnov D (2007) Order Coleoptera, family Elateridae. Arthropod fauna of the UAE 1: 270-292.

Toskina I (1998) Rare and new Anobiidae (Coleoptera) from the Arabian Peninsula. Fauna of Arabia 17: 51-91.

Uhmann G (1992) Die Anthicidae der Iberischen Halbinsel (Coleoptera, Anthicidae). Mitteilungen der Münchner Entomologischen Gesellschaft 82: 87-180.

Uhmann G (1998) Anthicidae (Insecta: Coleoptera) from Saudi Arabia with the description of a new species. Fauna of Arabia 17: 93-105.

Vesey-Fizberald DF (1957) The vegetation of Central and Eastern Arabia. Journal of Ecology 45: 779-798. https://doi.org/10.2307/2256957

Wittmer W (1979) Insects of Saudi Arabia, Coleoptera: Fam. Malachiidae, Dasytidae, Karumiidae. Fauna of Saudi Arabia 1: 186-192.

Ziani S, Gudenzi I (2012) Commenti sulla sistematica generica degli Scarabaeini del bacino del Mediterraneo con una chiave dicotomica per il loro riconoscimento (Insecta Coleoptera Scarabaeidae: Scarabaeinae). Romagna Quad. Studi Nat. Romagna 36: 115-158. 